NBSIR 82-2576

\title{
A Semiautomatic AC/DC Thermal Voltage Converter Calibration System
}

U.3. OEPARTMENT OF COMMERCE

Naticnal Dureau of Standard's

National Engineering Lacoratory

Center fcr EiEatronics and Electrical Engineering

E!tutiosvstens Uivision

Washingtcit. OC 20234

September 1982

Fina! Report

$-Q C=$ = ored in part by

10u Department of Defense

$.450^{\circ}$ ration Cosrdination Group

$32-2576$

1 Yú2

C. 2 



\section{A SEMIAUTOMATIC AC/DC THERMAL VOLTAGE CONVERTER CALIBRATION SYSTEM}

K. J. Lentner, S. G. Tremaine

U.S. DEPARTMENT OF COMMERCE National Bureau of Standards National Engineering Laboratory

Center for Electronics and Electrical Engineering Electrosystems Division Washington, DC 20234

September 1982

Final Report

Sponsored in part by:

U.S. Department of Defense

Calibration Coordination Group

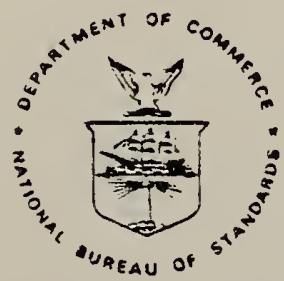

U.S. DEPARTMENT OF COMMERCE, Malcolm Baldrige, Secietary NATIONAL BUREAU OF STANDARDS, Ernest Ambler, Director 



\section{FOREWORD}

The development of the system described in this report was partially funded by the U.S. Department of Defense Calibration Coordination Group (DOD/CCG). Members of the DC and LF Committee were from the Aerospace Guidance and Metrology Center, Newark Air Force Station, Newark, Dhio 43055; the U.S. Army Metrology and Calibration Center, Redstone Arsenal, Huntsville, Alabama 35809; and the Metrology Engineering Center, Bureau of Naval Weapons Representative, Pomona, California 91766.

The DOD/CCG project number assigned was CCG 79-123, and work was performed under NBS cost center 7220463.

In order to adequately describe the system discussed in this report, commercial equipment and instruments are identified by manufacturer's name and model number. In no case does such identification imply recommendation or endorsement by the National Bureau of Standards, nor does it imply that the material or equipment identified is necessarily the best available for the purpose. 

Foreword

LIST OF TABLES

LIST OF FIGURES ........................ v

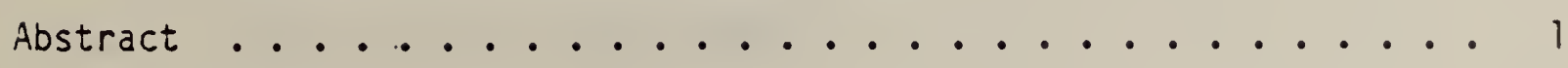

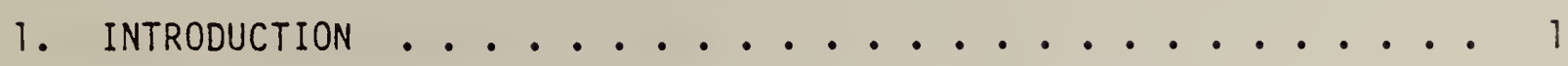

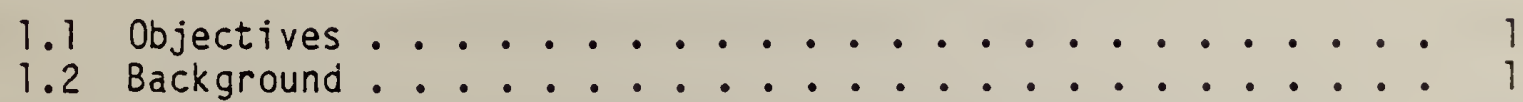

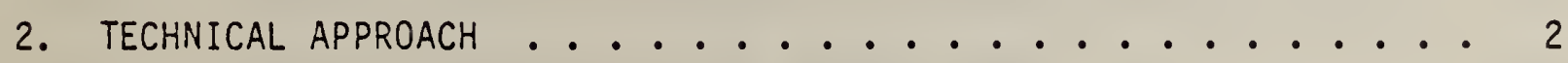

2.1 Principle of Operation ............. 2

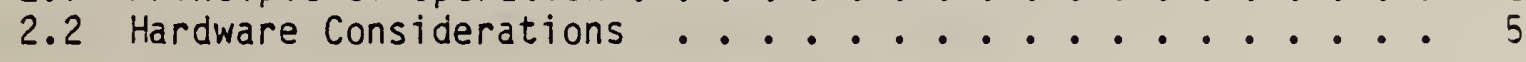

2.2.1 General ................ 5

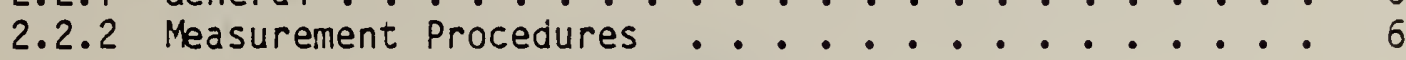

2.3 Software Considerations .............. 11

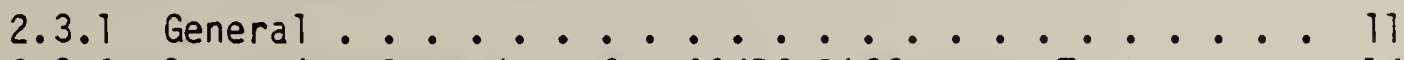

2.3.2 Operating Procedure for AC/DC Difference Tests ... 14

3. MEASUREMENT RESULTS AND UNCERTAINTIES . . . . . . . . . 20

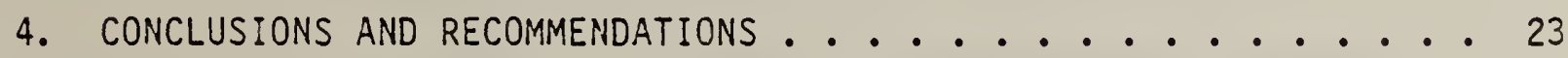

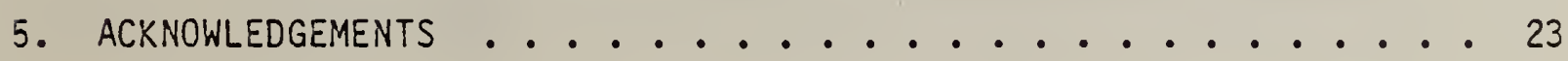

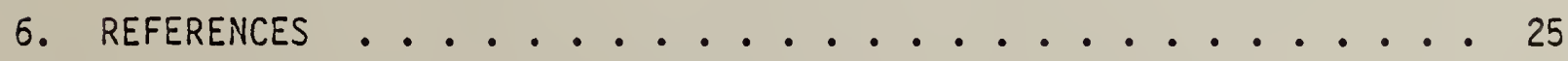

APPENDIX A. Hardware ................. 26

APPENDIX B. ACDCHV Detailed Program Description and Program Listing ............ 34 



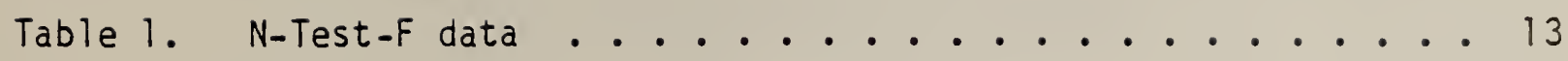

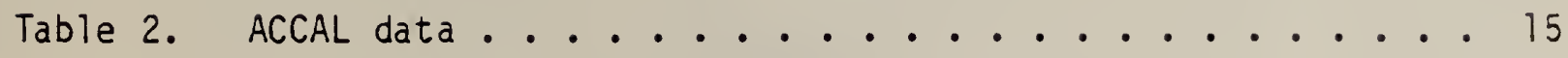

Table 3. Low voltage stability test data ......... 16

Table 4. Stability test data summary ............ 17

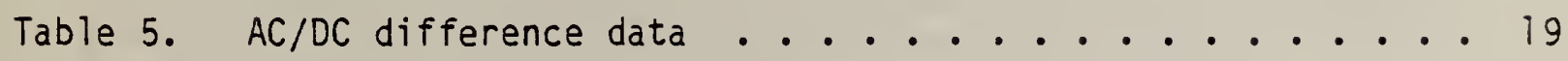

Table 6. Transport standard ac/dc differences $(p p m)$. . . . 21

Table 7. Range of ac/dc differences for transport standard (ppm) . 22

Table 8. AC/DC difference for TVC "FA 50" (ppm) ....... 24

Table 9. $A C / D C$ difference for TVC "FC 100" (ppm) ...... 24

\section{LIST OF FIGURES}

Figure 1. Overail view of system ............ 3

Figure 2. System block diagram ............. 4

Figure 3. Simplified schematic of thermal voltage converter (TVC) test circuit .............. 7

Figure 4. Block diagram of system for calibrating an ac standard or voltmeter 

A SEMIAUTOMATIC AC/DC THERMAL VOLTAGE CONVERTER CALIBRATION SYSTEM

\author{
K. J. Lentner and S. G. Tremaine
}

\begin{abstract}
A semiautomatic ac/dc difference calibration system is described. The system operates over a frequency range of $20 \mathrm{~Hz}$ to $100 \mathrm{kHz}$, covering the voltage range from $0.5 \mathrm{~V}$ to $1 \mathrm{kV}$. For all voltages at frequencies in the range from $20 \mathrm{~Hz}$ to $20 \mathrm{kHz}$, the total uncertainty is 50 parts per million (ppm), and $100 \mathrm{ppm}$ for voltages at frequencies between $20 \mathrm{kHz}$ and $100 \mathrm{kHz}$. In addition to ac/dc difference testing, the system can be readily adapted to calibrate precision ac digital voltmeters or ac calibrators. Results of extensive intercomparison testing of the new system against a manual test system are reported, using a multirange thermal transfer instrument as a transport standard. The results indicate that the ac/dc differences measured are well within the combined total uncertainty limits of the two systems.
\end{abstract}

Key words: ac/dc difference; ac voltage measurement; automation; calibration; metrology; thermal voltage converter.

\title{
1. INTRODUCTION \\ 1.1 Objectives
}

The Semiautomatic AC/DC Thermal Voltage Converter Calibration System, developed at the National Bureau of Standards and described in this report, was designed to use electronic technology to overcome the deficiencies of existing manual test methods. Specific objectives for the new system included: 1) use of commercially available, programmable instruments whenever possible; 2) el imination of the need for manual data entry into a computer for reduction; 3) elimination of the frequent data checks and cross-checks required in manual tests; 4) elimination of as much operator intervention as possible during the test procedure; 5) simplification of necessary remaining interaction by providing displayed operator instruction via computer control; 6) close control of the time interval betiveen application of both ac and dc voltages to the test circuit in order to minimize drift effects; and 7) achievement of the same level of uncertainty as is presently possible with manual testing methods.

\subsection{Background}

Techniques for performing precision ac/dc difference testing, not only at the National Bureau of Standards (NBS), but also in other national and industrial or governmental metrology laboratories, generally make use of manual testing methods which utilize photocell preamplifiers and lightbeam galvanometers as voltage detectors in conjunction with manually 
balanced voltage comparators $[1,2] .1$ Careful attention to the elimination or reduction of systematic and random uncertainties in testing methods, range resistors, and thermoelements (TE's) has resulted in sufficient confidence in test data to allow results to be reported with total uncertainties at the 10-100 ppm level (or better, in some cases) over wide voltage and frequency ranges $[3,4]$. These manual test methods, however, are very time-consuming and subject to errors due to operator fatigue. To overcome these deficiencies, and to expedite test report generation, a semiautomatic ac/dc calibration system was developed.

Because of the low-level dc voltages that must be measured (about $10 \mathrm{nV}$ ), large temperature coefficients of $T E^{\prime} s$, ac or dc source instabilities, and dc reversal differences of TE's, stringent requirements are placed upon the measurement system. In addition, light beam galvanometers suffer the disadvantage of not being easily adaptable to automation. However, with the advent of digital electronics, digital nanovoltmeters are available with sensitivity, resolution, and accuracy sufficient to meet the requirements of precision automatic ac/dc difference testing. Programmable ac and dc voltage calibrators are also available which lend themselves to adaption for automatic testing. Advances in analog/digital interfaces have greatly improved the ease with which computers can be used to control these instruments. The semiautomatic system which evolved is shown in figure 1, and is described in detail in this report. The system operates over a frequency range of $20 \mathrm{~Hz}$ to $100 \mathrm{kHz}$, covering the voltage range from $0.5 \mathrm{~V}$ to $1 \mathrm{kV}$. For all voltages at frequencies in the range from $20 \mathrm{~Hz}$ to $20 \mathrm{kHz}$, the total uncertainty is $50 \mathrm{ppm}$, and $100 \mathrm{ppm}$ for all voltages at frequencies between $20 \mathrm{kHz}$ and $100 \mathrm{kHz}$. In addition to $\mathrm{ac} / \mathrm{dc}$ difference testing, the system can be readily adapted to calibrating precision ac digital voltmeters or ac calibrators. Extensive testing of the new system using a multirange thermal transfer instrument as a transport standard indicates that the test results are well within the reported uncertainty limits. In addition, data obtained with the system indicate that total random uncertainties ( $3 \sigma$ limits) of about $3 \mathrm{ppm}$ can be obtained for some ac/dc difference tests.

\section{TECHNICAL APPROACH}

\subsection{Principle of Operation}

A block diagram of the semiautomatic system is shown in figure 2 . in principle, the system is similar to the manual system presently used at NBS for routine calibration work, except that overall system control and data acquisition and processing are provided by a 16-bit minicomputer. Programmable ac and dc standards supply the voltages to the thermal converters (consisting of the TE and various range resistors). Such voltage standards are often referred to as ac or dc calibrators. The output voltages of the two converters (as well as the difference between the two voltages) are measured in a semiautomatic mode by means of a

Numbers in brackets refer to the literature references listed at the end of this report. 


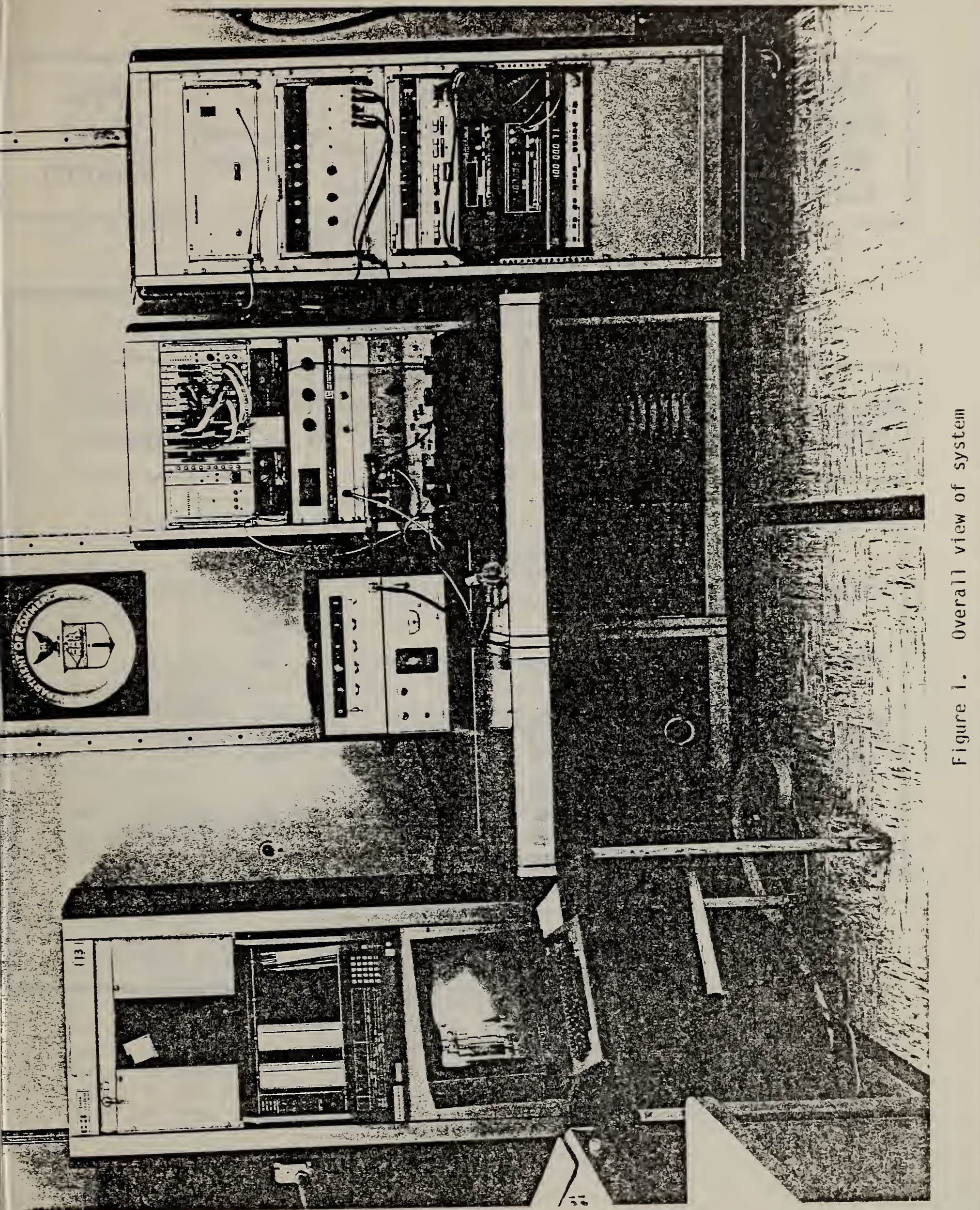




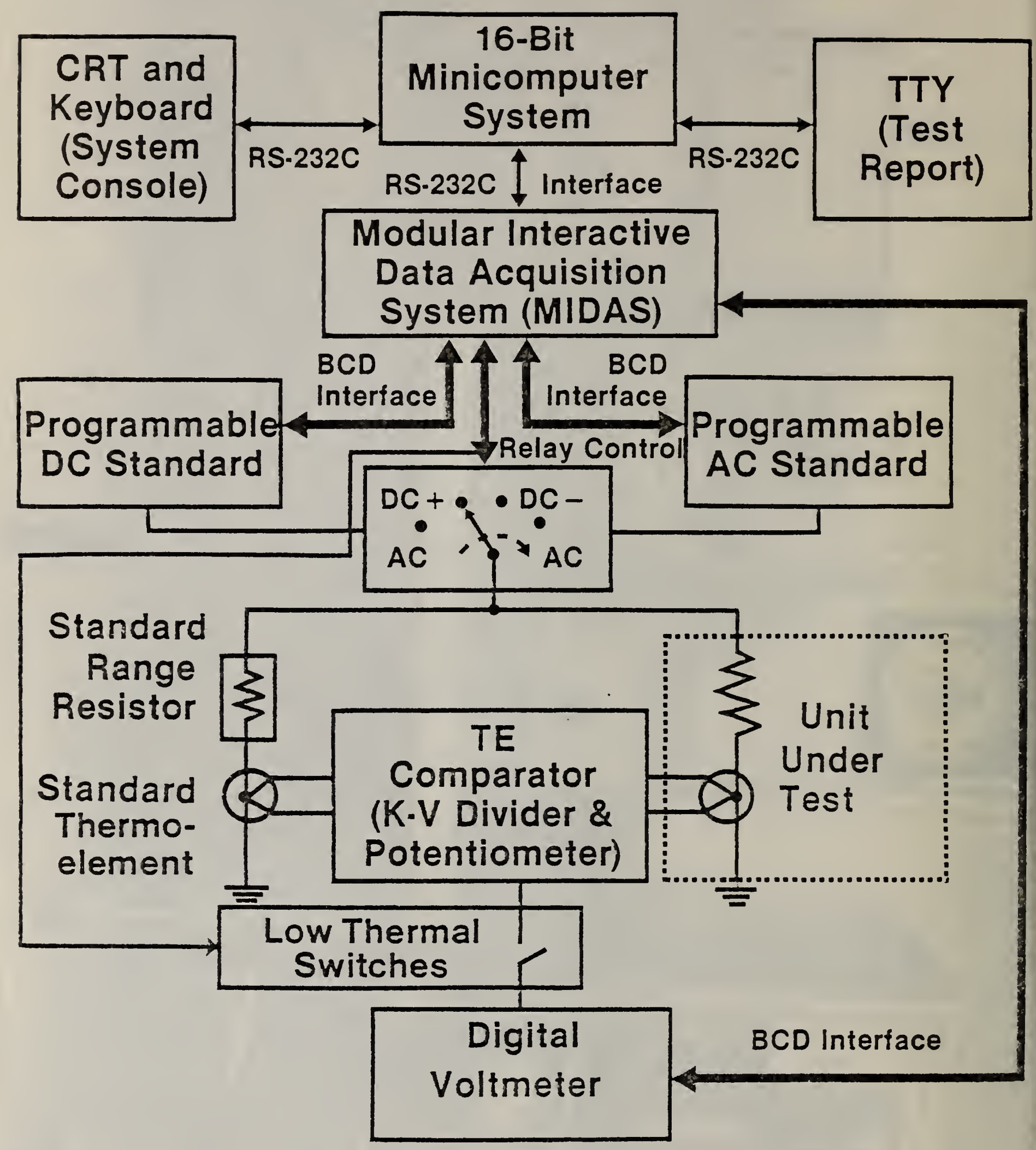


manually operated TE comparator and a digital voltmeter which is automatically controlled via the computer. The computer, its peripheral equipment, and the Modular Interactive Data Acquisition System (MIDAS) [5] are interconnected utilizing the standard RS-232C interface. The programmable instruments and the high voltage and low-thermal-noise switches are controlled by the computer via the MIDAS digital interface.

In operation, the ac or dc voltages are applied simultaneously to the standard TE and the unit under test (UUT). The difference in the output voltages is primarily balanced out by the TE comparator. The sma 11 residual differences in the TE output voltages are automatically measured with the digital voltmeter as the inputs are switched between the ac and dc voltages. Typically, the voltage differences are manually balanced to less than $100 \mathrm{nV}$. The residual voltages are then measured with a resolution of $10 \mathrm{nV}$, requiring a voltmeter with only moderate accuracy but with low noise. In addition, the voltmeter is used to measure the nominal output voltages of both converters.

\subsection{Hardware Considerations}

\subsubsection{General}

As mentioned previously, the components of the semiautomatic system (except for the computer, its peripheral equipment, and interfaces) are similar to manual systems used at NBS. The principle differences for the new system are the use of a sensitive digital voltmeter and programmable dc and ac voltage standards. A listing of the hardware contained in the system is provided in appendix $A$.

Overall system control is provided by means of a 16-bit minicomputer which has 64 kbytes of core memory and a dual floppy-disk unit for program and data storage. The system console (CRT), the teletypewriter (TTY), and MIDAS are connected to the computer by means of interfaces which conform to the EIA RS-232-C standard [6]. MIDAS hardware is based on the CAMAC standard [7] and consists of several functional modules which are inserted into slots in an equipment rack. A power supply and MIDAS controller module also are required to make the MIDAS system operational. Communication between the controller module and individual MIDAS modules is in accordance with the ASCII standard code for information interchange [8].

The $d c$ and ac voltage standards must have wide voltage and frequency ranges to meet the requirements of calibration work for which the system is intended. In addition, the standards must be stable and have sufficient resolution to permit precision measurements to be made. The dc voltage standard has ranges of $10 \mathrm{~V}, 100 \mathrm{~V}$, and $1 \mathrm{kV}$ with resolutions of $1 \mu \mathrm{V}$, $10 \mu \mathrm{V}$, and $100 \mu \mathrm{V}$ per step, respectively, with ten steps per range. The specified accuracy is about $30 \mathrm{ppm}$ of range for all three ranges, with output stability of about $15 \mathrm{ppm}$ of programmed output per month. The ac voltage standard has seven decade ranges covering the voltages from $1 \mathrm{mV}$ to $1 \mathrm{kV}$ (full-scale ranges) with a resolution of $10 \mathrm{ppm}$ of range per step, with ten steps per range. The frequency ranges consist 
of eleven fixed frequencies per range, covering the range $10 \mathrm{~Hz}$ to $110 \mathrm{kHz}$, with frequency range multipliers of $\times 10 \mathrm{~Hz}$ and $X 100 \mathrm{~Hz}, X 1 \mathrm{kHz}$ and $X 10 \mathrm{kHz}$. The accuracy of the ac standard's voltage output varies with frequency, from about $0.02 \%$ to $0.05 \%$ of voltage setting. The voltage stability is specified as $0.01 \%$ of setting for six months.

The digital voltmeter has eight ranges from $\pm 10 \mu \mathrm{V}$ to $\pm 100 \mathrm{~V}$. On the most sensitive $10 \mu \mathrm{V}$ range, it has a resolution of $10 \mathrm{nV}$, with an input impedance of about $10 \mathrm{M}$. The zero stability is specified as less than $100 \mathrm{nV}$ per hour. In the frequency range dc to about $10 \mathrm{~Hz}$, the voltmeter has less than $50 \mathrm{nV}$ of rms noise, referred to the input, with the input shorted.

It should be noted that two digital panel meters used to monitor the outputs of the voltage standards, as well as a frequency counter used to monitor the ac frequency, are not included in figure 2 (for simplicity), but they are visible in figure 1. The large instrument on the left of the test console table (fig. 1) is an ac calibrator under test.

A critical problem in making nanovolt measurements is that of obtaining switches which have low-thermal-noise, and can be controlled automatically. Ideally, TE output voltages of about $10 \mathrm{mV}$ should be measured to within $1 \mathrm{ppm}(10 \mathrm{nV})$. Mercury-wetted contact, self-latching, solid-state and reed relays were found to be unsuitable since these types have thermalnoise on the order of $1 \mu \mathrm{V}$. The problem was solved by modifying manualiy operated low-thermal-noise switches. Solenoids with 24-V operating coils were mechanically linked to such switches. The operating coils are energized by programmable MIDAS relays which connect the $24-y$ supply to the coils.

The switches which apply the ac or de voltages to the test circuit are electro-mechanical relays capable of switching up to $5 \mathrm{kV}$. The $24-\mathrm{V}$ operating coils of these relays also are controlled by MIDAS relays.

\subsubsection{Measurement Procedures}

The various measurement steps will now be explained in some detail for the determination of ac/dc difference, and for determination of the corrections to the nominal output voltages of an ac voltage standard.

A portion of the circuit for ac/dc difference testing, including the components of the TE comparator, is shown in figure 3 . The thermal voltage converter (TVC) No. 2 can be either the standard or test converter. The only requirement is that $E_{2}$ must be greater that $E_{1}$ and, for purposes of this discussion, it is assumed that the test TVC is in the No. 2 position. With rated dc voltage apolied, and with the potentiometer ( $P$ ) turned off, the emf outputs ( $E_{2}$ of the test unit, $E_{1}$ of the standard) are measured by the digital voltmeter (DVM) with switch $\mathrm{K} 2$ closed. Another switch in the TE comparator (not shown in fig. 3) permits 


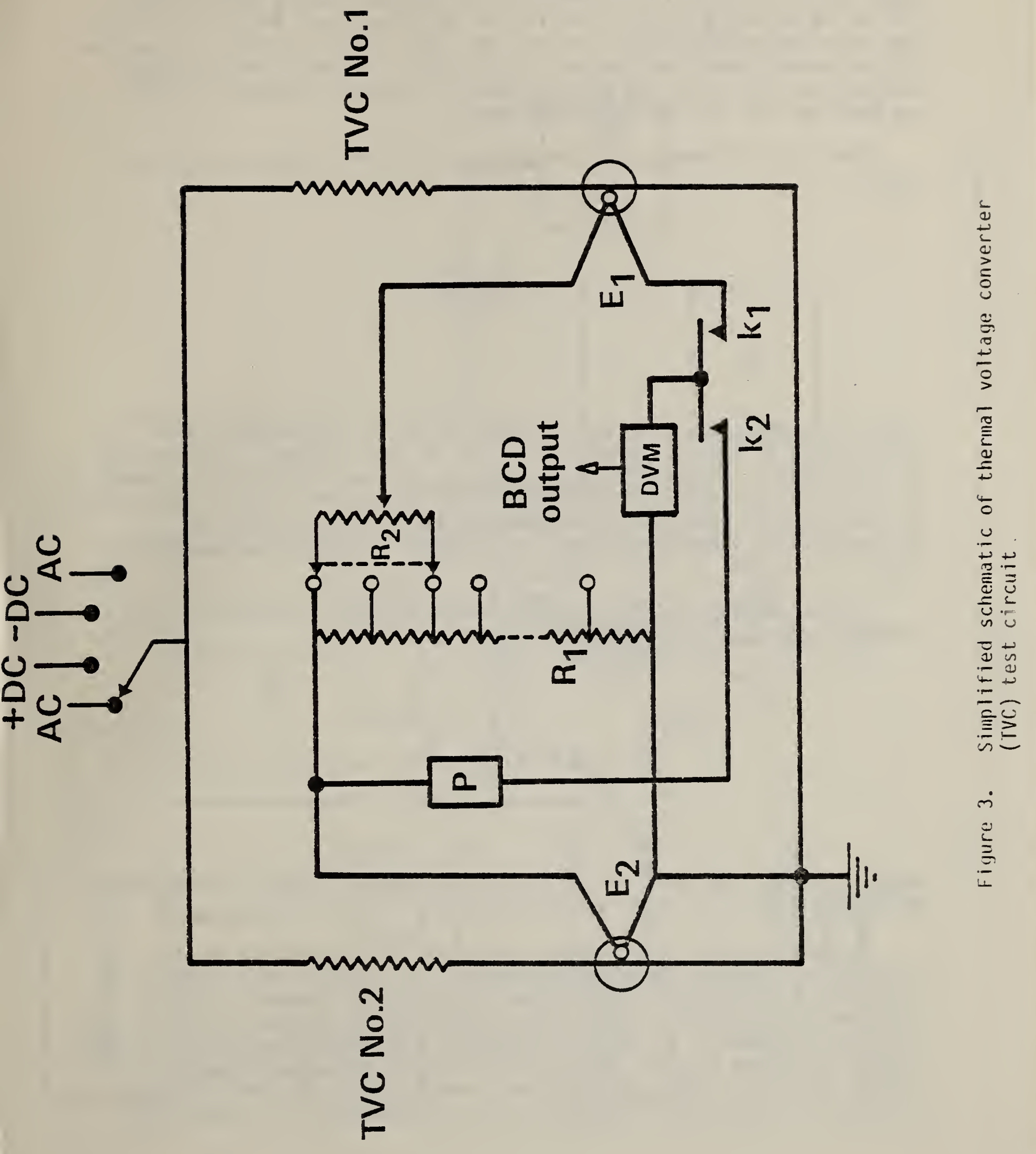


manual selection of either the $E_{2}$ or $E_{1}$ voltages. With the voltmeter reading $E_{2}$, the potentiometer is adjusted until the voltmeter indicates about $500 \mathrm{nV}$. Switch $\mathrm{K} 2$ is opened, $\mathrm{Kl}$ is closed, and the Kelvin-Varley divider is adjusted until the voltmeter indicates about $100 \mathrm{nV}$. The test then proceeds automatically, and $a c, d c+, d c-$, and $a c$ voltages are applied (in the order listed) to the test circuit [2]. The difference voltages between the outputs of the test and standard thermal voltage converters are measured for all four input voltages. [2], is

The ac/dc difference, in ppm, for the unit under test, as derived in

$$
\delta_{t}=\delta_{s}+\frac{E_{d}-E_{a}}{n_{s} E_{s}} \text {, }
$$

where os is the correction to the standard, $E_{d}$ is the average emf of the standard TE with two directions of dc voltage applied, Ea is the emf of the standard TE with ac voltage applied, $\mathrm{n}_{\mathrm{s}}$ is a dimensionless iactor $(\leq \cdot 2)$ of the standard, and $E_{S}$ is the output emf of the standard $T E$ at rated d $\bar{c}$ voltage input. If $E_{d}-E_{a}$ is measured in nanovolts, and $E_{s}$ in millivolts, the expression for $\delta_{t}$ is conveniently given in ppm, provided that $\delta_{s}$ is in ppm.

If the standard TE has a higher output emf than the test $T E$, the previous expression is modified to become

$$
\delta_{t}=\delta_{s}+\frac{E_{d}-E_{a}}{n_{s} E_{t}},
$$

where all terms and units are as previously defined, and $E_{t}$ is the output emf of the test TE at rated dc voltage input.

A block diagram of the system when used for calibrating an ac standara or voltmeter is shown in figure 4. As shown in this figure, the system's ac standard is connected for testing. However, the UUT, indicated as "AC STD," could as well be an external ac standard or a precision voltmeter. $K 1$ and $K 2$ are the dct and dc-high voltage switching relays, $K 3$ is the ac high voltage relay, and $K 4$ is a low-thermal-noise switch. Using this test circuit, the corrections to the nominal output voltage (at a given dial setting) of an ac standard can be determined 


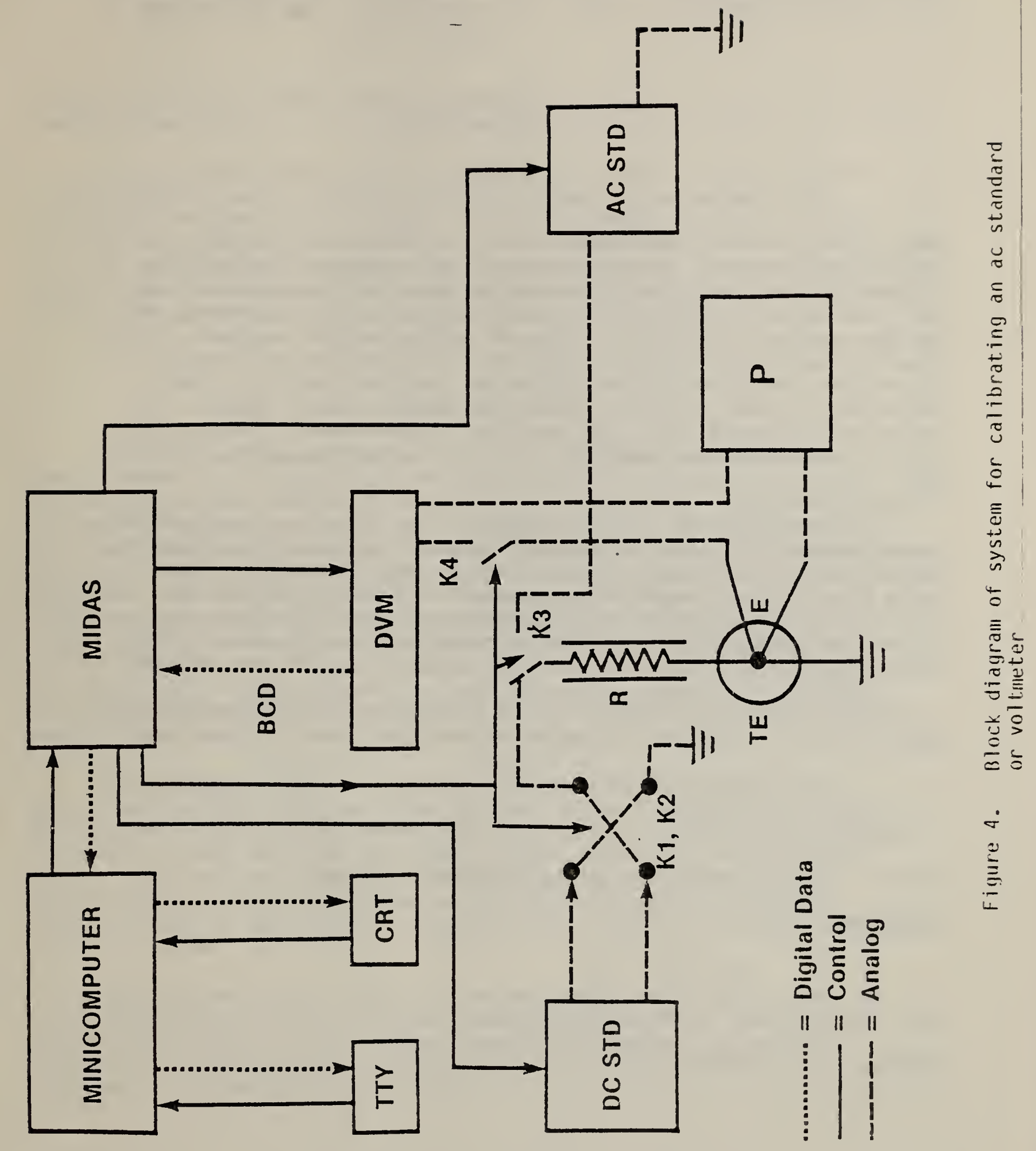


by using the system's programmable dc voltage standard (set to the same nominal value as the ac standard) and a thermal voltage converter, both having known corrections. For this case, only the Lindeck potentiometer (P) of the TE comparator is used. The correction to the UUT, in ppm, is

$$
C_{t}=\delta_{s}+\frac{E_{a}-E_{d}}{n E}+C_{d c}
$$

where $\delta s$ is the ac/dc difference correction (in ppm) of the TVC at the test frequency, $E_{a}$ is the reading of the voltmeter (DVM) with ac voltage applied ( $i . e$. , the difference between the TE's output emf and the fixed voltage of the Lindeck potentiometer), $E_{d}$ is the average of the DVM readings with direct voltage of both polarities applied, $n$ is a dimensionless factor equal to 2 if the TE has a square-law response, $E$ is the TE's output emf at the applied test voltage, and $C_{d c}$ is the correction (in ppm) to the dc voltage standard's nominal output. As for ac/dc difference tests, the equation is conveniently given in ppm if $E_{a}-E_{d}$ is in nanovolts and $E$ is in millivolts, with $\delta_{s}$ and $C_{d c}$ also in ppm.

The denominator of the correction equation contains the dimensionless characteristic " $n$." Most TE's do not have an ideal square-law response, hence, the value of $n$ must be determined. Since $n$ generally ranges in value from 1.6 to 2 , neglecting to measure a TE's actual value of $n$ - can lead to significant errors in the correction to the UUT. For example, in the worst case, if $n$ is assumed to be 2 , but actually is 1.6 , then the error amounts to $(2-1.6) /(2)=0.2$, or 20 percent of the correction.

The procedure for measuring $n$ (to a first order of approximation) is based on the fact that a TE's output voltage (E) can be expressed as

$$
E=k I^{n} \text {, }
$$

where $I$ is the current through the TE's heater element.

Therefore,

and

$$
d E=k n I^{n-1} d I \text {, }
$$

Hence, $\quad d E / E=n(d I / I)$, 
and, assuming constant heater resistance and a stable voltage source,

$$
d E / E \simeq n(d V / V),
$$

where $V$ is the dc voltage applied across the series combination of a range resistor and a TE.

Two techniques can be used to measure the characteristic n. One involves making small, accurately known changes in the voltage $(\Delta V)$. The second involves making changes in the TE's heater current (I) with the applied voltage held constant. In the second method, which is used for the MIDAS-based system, small changes in the heater current through the TE under test are obtained when a $400 \Omega$ resistor, in series with a $40 \mathrm{k} \Omega$ range resistor, is shorted by closing a MIDAS relay.

\subsection{Software Considerations}

\subsubsection{General}

In order to reduce the effort involved in making routine tests, the software for the system was designed to provide as much interaction between the system console and the operator as possible. This interaction is used to reduce the possibility of damage to either the standard or UUT when either software or hardware failures occur. Also, by progressing logically through the initialization portions of the test routines, the operator, when necessary, can take whatever corrective actions might be required. A significant advantage of the resulting software design is that sufficient warm-up time is automatically provided between application of the various test voltages so that the effects of errors due to the warm-up drifts of the standard and test units are reduced. In addition, the computer closely controls the time intervals between voltmeter readings; hence, the effects of linear drift are minimized.

The programs, which are written in BASIC, provide the means for automatically setting the ac or dc voltages and ac frequency, operating the voltage relays and low-thermal-noise switches, triggering the voltmeter to obtain voltage readings, and storing these readings in the computer memory. Six programs constitute the major testing software package. Program ACDCLV is used for making ac/dc difference tests at voltages from 0.5 to $95 \mathrm{~V}$, and ACDCHV is used for similar tests at voltages greater than $105 \mathrm{~V}$ up to $1 \mathrm{kV}$.

Since the major application of the work described in this report is ac/dc difference testing, a typical sequence of operations for this type of testing is described below where the ACOCHV program is discussed. The other five programs will only be mentioned briefiy; however, detailed information is available upon request. 
ACDCHV is a program which provides partial automatic control of $\mathrm{ac} / \mathrm{dc}$ difference testing at voltages greater than $105 \mathrm{~V}$. Since the MIDAS interface does not have isolated analog and digital grounds, it was necessary to develop a separate software package for high-voltage testing. At high voltages, it was found that operating either the ac or dc voltage relays introduced transient voltage surges into the MIDAS digital circuitry. The MIDAS controller interpreted these surges as voltage level changes identical to programmed commands. The result was that incorrect relays might be opened or closed, the voltmeter might be falsely triggered to obtain a reading, or any other of a series of unwanted events might occur. Hence, the ACDCHV program was developed to ensure that no high-voltage standards are turned on whenever a voltage relay is operated. To avoid unnecessary operation of the high-voltage relays, program ACDCLV should be used for tests below $100 \mathrm{~V}$.

Basically, ACDCHV contains three general sections. At the beginning, test documentation (e.g., date, test number, observer, and instrument) is requested. String and array variables are dimensioned, and various simple variables are initialized. A heading for the test documentation is created by the operator. The midsection includes a network of subroutines that interact with the operator. Displayed instructions prompt the operator to define test parameters for setting ac and dc voltages, to switch the TE comparator from E-high to E-low, and to initially balance the Kelvin-Varley divider and rebalance it when necessary. Repeatedly accessed subroutines close and open the appropriate relays, set the input voltages, determine the TE emf output voltages, trigger the voltmeter to read the $T E$ difference voltages, and calculate the ac/dc difference of the UUT for four determinations at each test point. Finally, statistical calculations are performed and the results are printed on the TTY. Options are then provided for the operator to choose whether to stop, repeat a test with or without averaging, or change parameters and run another test.

Program NTSTF is used to determine a TE's dimensionless factor, $n[1,2]$. The variation of $n$ as a function of a TE's heater current can be expressed as $n \approx g(E)$, and this function is assumed to vary linearly. The program automatically fits a least-squares line to the data. The computational techniques used are fully discussed on pages 5-10 of [10]. Typical test results are illustrated in table 1. 
Table 1. N-Test-F data

DATE . . . THUR. 29 MARCH 79

TEST NO. . . N-TEST

VOLTS

E

100

2.70

(1.992

2.70

(1.988

$3.88 \quad(1.973$

3.88

(1.973

$(1.954$

5.24

5.24

(1.954

6.79

(1.922

6.79

(1.922

8.50

(1.88

8.50

(1.878

10.34

(1.833

$(1.826$

N

1.991

1.973

200

10.34

1.832
INST NO. . . FA

AVE.N NE

$500 / N$

1.990

1.990)

1.991

5.37

5.37

7.66

$1.989 \quad 1.991)$

1.990

1.974

7.66

1.974

10.25

10.25

1.955

13.06

1.923

13.06

1.923

13.06

16.00

15.99

18.96

18.95

251.2

251.3

253.3

253.3

255.7

255.7

260.0

260.0

265.7

265.8

272.7

1.834

1.834 )

1.833

272.8

THE CURVE FITTING PROCESS USES A LEAST-SQUARES FIT FOR A POLYNOMIAL OF DEGREE ONE. THE N (LOWER CASE) TE CHARACTERISTIC ( $Y$-AXIS) VERSUS TE EMF ( $X$-AXIS) IS ASSUMED TO BE A LINEAR FUNCTION OF THE FORM $Y=B+M X$ OR, IN THIS CASE:

$$
N I=M-N E
$$

WHERE NI = TE CHARACTERISTIC

$$
\begin{aligned}
& M=\text { ZERO } X \text { INTERCEPT } \\
& N=\text { NEGATIVE OF CURVE SLOPE } \\
& E=\text { TE OUTPUT EMF }
\end{aligned}
$$

$M=\ldots .2 .05518$

$\mathrm{N}=\ldots . .206568 \mathrm{E}-1$ 
ACCAL is a program used to calibrate an ac voltage standard, a precision ac digital voltmeter, or the ac standard of the system in terms of a thermal voltage converter and the system's calibrated dc standard, as discussed in the previous section. Results for the calibration of an ac voltage standard are illustrated in table 2. The last column, "T CORR PPM," shows the correction to the calibrator's nominal output voltage.

Stability of the system's dc and ac standards can be checked by using programs called STABLV and STABHV. These progams are used for voltage ranges similar to those for ACDCLV and ACDCHV. Occasionally, test results appear to be erratic. These stability tests are useful in determining if the supplies are functioning properly. Stability of the sources is measured by using a programmable 6-1/2 digit multimeter whose function, ranges, and reading rates are remotely controlled. Initial stability test parameters for voltage, frequency, time between readings, and total number of readings are defined by the operator. The program then exercises automatic control over the ac and dc standards, the voltage relays, and the voltmeter. At completion, stability data including the values of minimum, maximum, range, average, standard deviation of the mean, and three times the standard deviation of the mean (calculated 30 limits) for both ac and dc voltage readings are printed on the TTY. Table 3 shows the results of a test at $95 \mathrm{~V}$, $50 \mathrm{kHz}$, with the voltmeter programmed to use a 10-second integration time. The total time for the test illustrated was about 12 minutes, which is about the time it takes to do a test run (i.e., four determinations) for ac/dc difference tests at one frequency and voltage.

The advantages of the stability tests are illustrated in table 4. The difference in the ranges of the ac voltage for tests at $95 \mathrm{~V}$ and $200 \mathrm{~V}$ indicates that the ac high-voltage amplifier had become unstable. The instability was verified by a 12 -minute test in which the ac voltage range was about $1150 \mathrm{ppm}$ at $20 \mathrm{~V}$ as opposed to about $347 \mathrm{ppm}$ at $95 \mathrm{~V}$.

In addition to the test capabilities discussed above, the methodology and computer programs were developed for testing one model of a precision multirange automatic thermal transfer instrument as a voltmeter. Detailed information is available and can be supplied upon request.

\subsubsection{Operating Procedure for AC/DC Difference Tests}

For the reader not interested in the operational details of this program (contained in appendix B), the following overview is provided. The specific operating procedures include the following steps and instructions:

1) Input via the system console, the test number, voltage, frequency, observer's name, and code for the standard thermal converter.

2) Visualiy check to see that both software and hardware are operating correctly by checking the system's digital panel meters and frequency meter for correct readings of the outputs from the ac and $d c$ standards. If the outputs are incorrect, repeat step 1. 
Table 2. ACCAL data

DATE. . . . . . . . OBSERVER. . . . . .

TEST NO . . . . . . INST. . . . . . . . . .

$\begin{array}{rlllll}\text { KHZ CORR } & V & \text { TEST } & \text { STANDARD } & E & \text { NE } \\ \text { PPM } & & \text { RANGE } & \text { TE RANGE } & \text { MV } & \end{array}$ $\begin{array}{llllll}100.0 & 100.0 & \text { FB } & 100.0 & 10.4 & 18.6\end{array}$

0.80

$\left(\begin{array}{llll}7 & 8 & 7 & 10\end{array}\right)$

$0.8 \quad 0$

$\begin{array}{lll}(7 & 6 & 7\end{array}$

$0.8 \quad 0$

$\begin{array}{lll}7 & 8 & 8\end{array}$

3)

$0.8 \quad 0$

$\left(\begin{array}{lll}5 & 1 & 4\end{array}\right.$

2.40

$\begin{array}{lll}29 & 32 & 33\end{array}$

2.40

$\begin{array}{lll}30 & 35 & 34\end{array}$

2.40

$\begin{array}{lll}(32 & 35 & 25\end{array}$

2.40

(31 $31 \quad 32$

$4.8 \quad 0$

$\begin{array}{lll}278 & 282 & 281\end{array}$

$4.8 \quad 0$

$\begin{array}{lll}278 & 284 & 284\end{array}$

$4.8 \quad 0$

$\begin{array}{lll}278 & 284 & 284\end{array}$

$4.8 \quad 0$

(281 $283 \quad 285$

283)

0.40

$\begin{array}{lll}11 & 13 & 10\end{array}$

9)

0.40

(3) 389

8)

0.40

(5 $38 \quad 9$

9)

0.40

$\begin{array}{lll}5 & 9 & 11\end{array}$

8)

$\begin{array}{cc} & \begin{array}{c}\text { T CORR } \\ \text { PPM }\end{array} \\ & \\ -8 & -8 \\ -7 & -7 \\ -7 & -7 \\ -6 & -6 \\ & \\ 32 & 32 \\ 33 & 33 \\ 33 & 33 \\ 33 & 33 \\ & \\ 281 & 281 \\ 282 & 282 \\ 282 & 282 \\ 283 & 283 \\ 11 & 11 \\ 8 & 8 \\ 8 & 8 \\ 8 & 8\end{array}$


Table 3. Low voltage stability test data

\begin{tabular}{|c|c|c|c|c|}
\hline READING & DC-VOLTAGE & PPM & AC-VOLTAGE & PPM \\
\hline NO. 1 & 95.00530 & 55.9 & $\star \star \star \star$ & $\star \star \star \star$ \\
\hline NO. $1(A)$ & 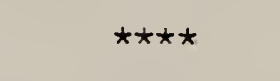 & $\star \star \star \star$ & 94.51200 & -5136.9 \\
\hline NO. 2 & 95.00530 & 55.9 & 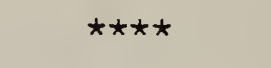 & 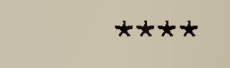 \\
\hline NO. $2(A)$ & 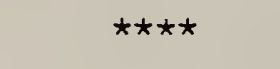 & $\star \star \star \star \star$ & 94.51300 & -5126.3 \\
\hline NO. 3 & 95.00530 & 55.9 & $\star \star \star \star$ & 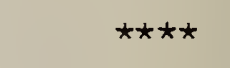 \\
\hline NO. 3 (A) & $\star \star \star \star$ & 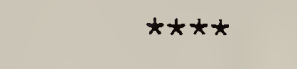 & 94.51200 & -5136.9 \\
\hline NO. 4 & 95.00540 & 56.5 & 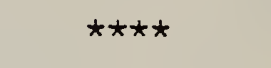 & 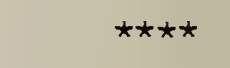 \\
\hline No. 4 (A) & 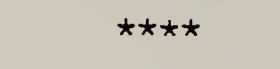 & $\star \star \star \star \star$ & 94.51200 & -5136.9 \\
\hline NO. 5 & 95.00530 & 55.9 & $\star \star \star \star$ & 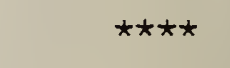 \\
\hline NO. $5(A)$ & 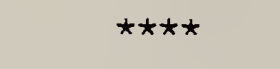 & $\star \star \star \star \star ~$ & 94.51200 & -5136.9 \\
\hline NO. 6 & 95.00530 & 55.9 & $\star \star \star \star$ & $\star \star \star \star$ \\
\hline No. $6(A)$ & $\star \star \star \star$ & 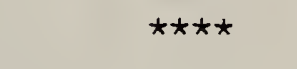 & 94.51100 & -5147.4 \\
\hline NO. 7 & 95.00510 & 54.0 & 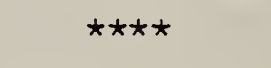 & 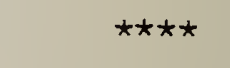 \\
\hline No. $7(A)$ & 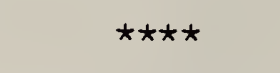 & 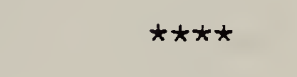 & 94.51000 & -5758.0 \\
\hline NO. 8 & 95.00510 & 54.0 & 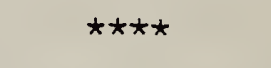 & 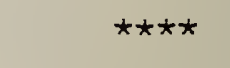 \\
\hline NO. $8(A)$ & 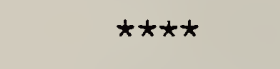 & $\star \star \star \star \star$ & 94.50800 & -5179.0 \\
\hline NO. 9 & 95.00520 & 54.6 & 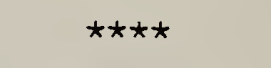 & 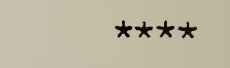 \\
\hline NO. $9(A)$ & 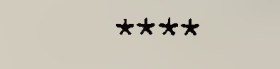 & 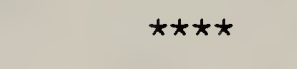 & 94.50700 & -5189.4 \\
\hline NO. 10 & 95.00510 & 54.0 & 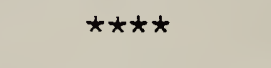 & 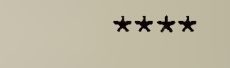 \\
\hline No. $10(A)$ & $\star \star \star \star$ & 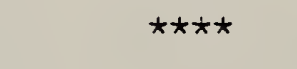 & 94.50700 & -5189.4 \\
\hline $\begin{array}{l}\text { DC } \\
\text { NO. OF } \\
\text { READINGS }\end{array}$ & $\begin{array}{l}\text { MEAN } \\
\text { (PPM) }\end{array}$ & $\begin{array}{l}\text { STAN. DEV. } \\
\text { OBSERVATION }\end{array}$ & $\begin{array}{l}\text { STAN. DEV. } \\
\text { MEAN }\end{array}$ & $\begin{array}{l}\text { STAN. DEV } \\
\text { MEAN } * 3\end{array}$ \\
\hline 10 & 55.3 & 1.0 & 0.3 & 1.0 \\
\hline MIN $=53.9679$ & \multicolumn{2}{|c|}{$\operatorname{MAX}=56.5378$} & \multicolumn{2}{|c|}{ RANGE $=2.5699$} \\
\hline $\begin{array}{l}\text { AC } \\
\text { NO. OF } \\
\text { READ INGS }\end{array}$ & $\begin{array}{l}\text { MEAN } \\
(\text { PPM) }\end{array}$ & $\begin{array}{l}\text { STAN. DEV. } \\
\text { OBSERVATION }\end{array}$ & $\begin{array}{l}\text { STAN. DEV. } \\
\text { MEAN }\end{array}$ & $\begin{array}{l}\text { STAN. DEV } \\
\text { MEAN *3 }\end{array}$ \\
\hline 10 & -5153.7 & 23.9 & 7.5 & 22.6 \\
\hline$M I N=5189.43$ & \multicolumn{2}{|c|}{ MAX $=-5126.31$} & \multicolumn{2}{|c|}{ RANGE $=63.1211$} \\
\hline $\begin{array}{l}\text { V-NOMINAL } \\
95\end{array}$ & $\begin{array}{l}\text { FREQUENCY } \\
50 \mathrm{kHZ}\end{array}$ & $\begin{array}{l}\text { INT. TIME } \\
10 \mathrm{SEC}\end{array}$ & $\begin{array}{l}\text { TIME DELAY } \\
10\end{array}$ & \\
\hline
\end{tabular}


Table 4. Stability test data summary

Program: STABLV - Overnight (17 hr) Test

DC

No. of

Readings

50

Min $=36.7817$

$A C$

No. of

Readings

50

Min $=84.1643$

V-Nomina 1

95

$D C$

No. of

Readings

50

$\operatorname{Min}=9.99451$

$A C$

No. of

Readings

Min $=-25400$

$V$-Nominal

200

$D C$

No. of

Readings

10

Min $=9.99451$

AC

No. of

Readings

Mean
(PPM)
216.6
Frequ
1
Pro

(PPM)

Stan. Dev. Observation

Stan. Dev.

5.0

$\operatorname{Max}=56.5378$

Mean

Stan. Dev.

Mean *3

42.1

0.7

Range $=19.7561$

2.1

Stan. Dev. Stan. Dev.

Observation Mean

Stan. Dev.

Mean *3

$276.6 \quad 51.0$

$\operatorname{Max}=437.583$

7.2

21.6

Range $=347.419$

Frequency

$1 \mathrm{kHz}$

Int. Time

Time Delay

$10 \mathrm{sec}$

57500

Program: STABHV - Overnight (17 hr) Test

Mean

Stan. Dev.

Observation

Stan. Dev.

Mean

Stan. Dev.

2.7

$\operatorname{Max}=19.989$

0.4

Range $=9.99451$

Mean *3

1.1

Stan. Dev. Stan. Dev.

Observation Mean

Stan. Dev.

Mean $* 3$

60.5

181.6

428.0

$\operatorname{Max}=-23450$

Range $=1949.99$

Frequency

$50 \mathrm{kHz}$

Int. Time

Time Delay

Program: STABHV - 12 Minute Test

$10 \quad-3890.0 \quad \operatorname{Max}=-23600$

Min $=-24750$

V-Nomina 1

200
Mean Stan. Dev. Stan. Dev. Observation Mean

0.0

$\operatorname{Max}=9.99451$

Stan. Dev. Stan. Dev.

Observation Mean

137.2

Range $=1149.98$
Stan. Dev.

Mean *3

0.0

Stan. Dev.

Mean $* 3$

471.6
Frequency

$50 \mathrm{kHz}$

Int. Time

Time Delay

$10 \mathrm{sec}$

5 
3) Manually set the TE comparator to its "high TE" voltage input position, and switch the voltmeter to its $10-m V$ range. The program automatically closes the de voltage relay and a-low-thermal-noise switch (K2) turns on the dc standard and triggers the voltmeter to obtain the TE voltage output reading.

4) Switch the TE comparator to its "low TE" voltage input position. The program then triggers the voltmeter to read the voltage. The values of the high- (from the previous step) and low-voltage readings are compared. If the latter is actually larger in magnitude than the former, the operator is instructed to interchange the two TE inputs after the dc voltage has been turned off. The program automatically stores the correct value of E-low, since that value is used in the equation to determine the ac/dc difference of the test unit (see section 2.2).

5) Switch the TE comparator to the "high TE" voltage input position. This step in the procedure is done only if the test unit actually has a greater emf output than the standard. If not, the comparator switch remains in the "low TE" voltage input position. In either event, the operator is then instructed to turn on the Lindeck potentiometer, change the voltmeter to its $10 \mu V$ range, and manually adjust the potentiometer until the voltmeter indicates about $500 \mathrm{nV}$.

6) Switch $K 2$ is opened, and a second low-thermal noise-switch (KI) is closed. The operator now manually adjusts the Kelvin-Varley divider until the voltmeter indicates a voltage within the range $\pm 100 \mathrm{nV}$.

7) Switch $K 1$ is opened, $K 2$ closed, the ac voltage relay is closed, the ac standard turned on, and its voltage is automatically incremented or decremented until the output voltage of the UUT'S TE is $\leq 1 \mu V$ of its value with de voltage applied, as in step 6 .

8) At this point, the manual initialization process is complete, switch $K 2$ is opened, $K 1$ is closed, and the test proceeds automatically under program control. A sequence of voltage readings is obtained by the voltmeter when ac, dct, dc-, and ac voltages are applied to the standard thermal voltage converter and UUT. These four voltage readings are each obtained from the average of ten readings of the voltmeter. The standard deviation of the ten readings is computed, and if this value is < $200 \mathrm{nV}$, the program continues. If the standard deviation is $>200 \mathrm{nV}$, due to drifts in either the standard converter or the UUT, or the ac or dc standards, or any of these effects combined, the series of ten readings is repeated. After five attempts, if the voltmeter readings have not stabilized, the test is aborted.

9) The sequence of readings with ac, dct, dc-, and ac voltages applied constitutes one determination of the ac/dc correction to the UUT. The process is continued for four determinations; the average value of four determinations is computed and printed. The operator then may elect to repeat the test, change voltage range or frequency, or stop the test. A sample of data printed on the teletypewriter is illustrated in table 5. Although only low-voltge test results are shown, the data format is identical for high-voltage tests. 
Table 5. AC/DC difference data

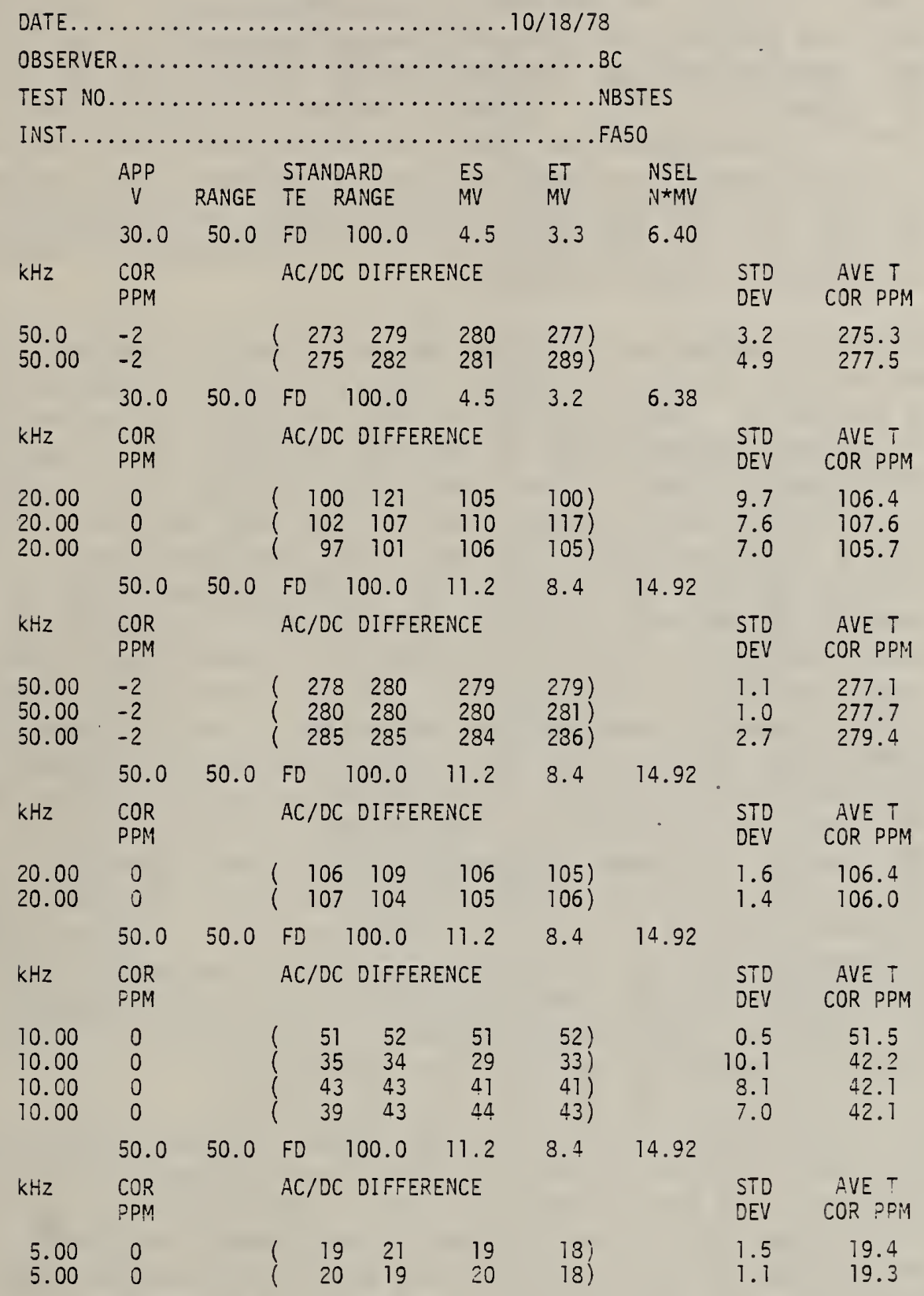

NUMBER OF READINGS $=H=\ldots \ldots \ldots \ldots 64$

NUMBER OF INDEP. TESTS $=\mathrm{L}=\ldots \ldots \ldots . \overline{0}$

DEGREES OF FREEDOM $=01=\ldots \ldots \ldots \ldots 58$

POOLED ESTIMATE OF TEST STD.DEV. OF MEAN $=$ S2

=5.D.T. (SEE S.P. 300, V.1, P. 316-40) .... = $=1.02083$ 


\section{MEASUREMENT RESULTS AND UNCERTAINTIES}

There are many factors which contribute to the uncertainty of ac/dc difference measurements of the type described in this report. Similar manual systems have been in operation for many years at NBS and their uncertainties have been documented [1-3]. DC reversal difference of a TE, self-heating and ambient temperature effects, drift effects due to non-equal time intervals during the voltage measurements, unbalanced lead impedances, and induced voltages from electromagnetic fields are some of the more common factors. The process of determining an estimated total uncertainty for a system is based upon experience with the system, careful measurements of standards with accurately known corrections, or intercomparison tests of two independent test methods [3]. The latter procedure, involving comparison of a well-characterized manual system with the new one, was followed, since the uncertainty sources are believed to be similar in both systems.

The system performance was verified by an extensive testing procedure which involved the use of a multi-range thermal voltage converter instrument as a transport standard. The transport standard was first tested for ac/dc differences at various combinations of applied voltages and frequencies using the MIDAS-based system. It was then tested, at similar voltages and frequencies with the same standard thermal voltage converters, using the manual testing technique which has been used for many years at NBS. A third test was performed, again using the MIDAS system. Finally, the MIDAS system was disassembled, physically relocated, reassembled, and tested for proper operation. Then the transport standard was tested a fourth time, again using the MIDAS system. It should be noted that not all voltage range-frequency combinations were tested for all four tests. However, in those cases where fewer than four tests were performed, the results indicated sufficiently small differences between at least two independent test methods to establish that further testing was not warranted. The results of these independent intercomparison tests are listed in table 6 , and the range of ac/dc differences is listed in table 7. In evaluating these results, it must be remembered that, for calibrating multirange instruments like the transport standard, the manual test system has uncertainties of the same magnitude as the semiautomatic system. Hence, combined total uncertainties of the order of 100 and 200 ppm are possible depending upon the test frequency.

In table 7 , the column listing "Voltage Range" refers to the input voltage range of the transport standard, the "Test Voltage" is the actual test voltage applied, and the different columns for frequency are the actual test frequencies used. The numbers listed under the frequency columns are the maximum differences (in ppm) of the calibrated ac/dc difference corrections for the transport standard as determined for at least two, and up to a maximum of four, of the test conditions described above. That is, the numbers reported are the range (magnitude of the maximum minus the minimum) of the ac/dc difference corrections measured for each test voltage and frequency. The total elapsed time between the first and final tests of the transport standard was about eight weeks. 
|

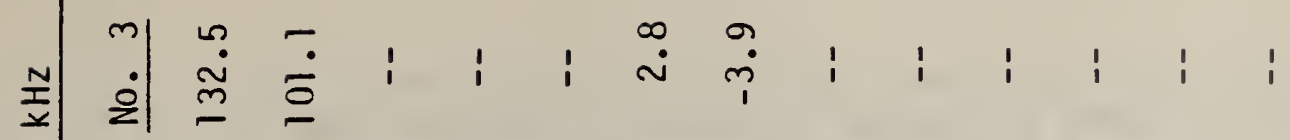

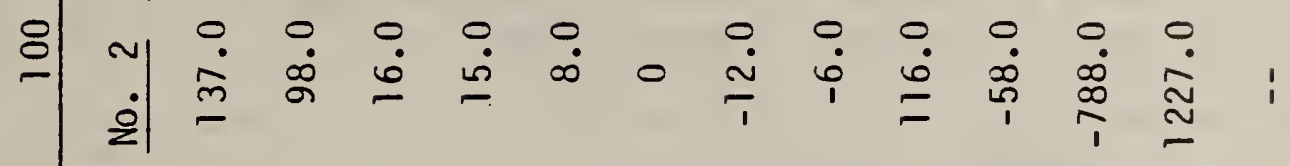

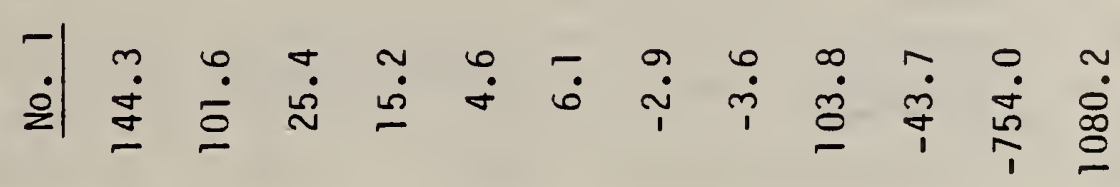

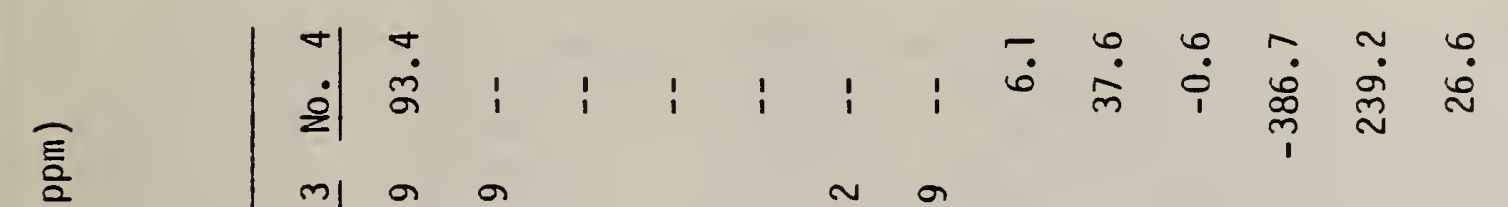

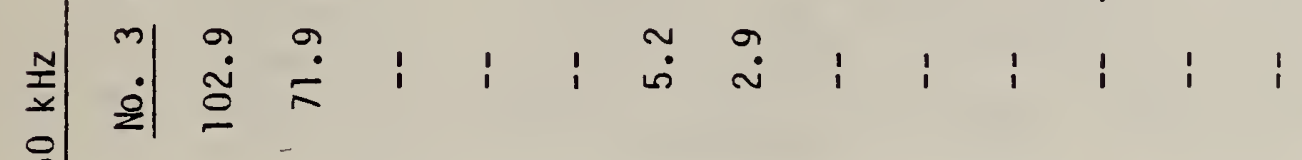

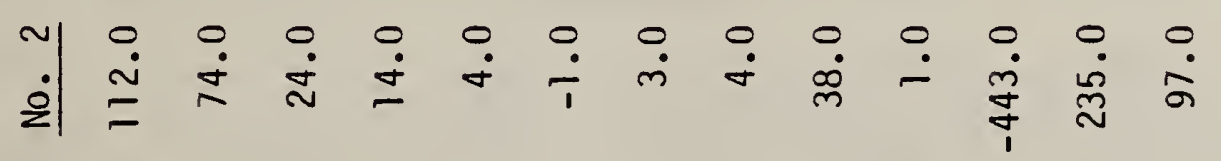

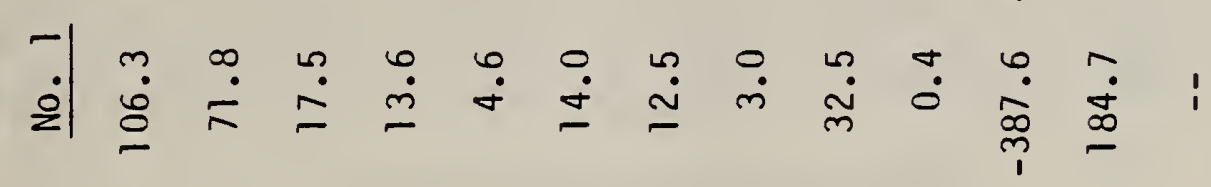

总

(2)

$\frac{1}{5}$

竎

$\underbrace{0}_{0}$

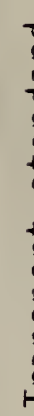

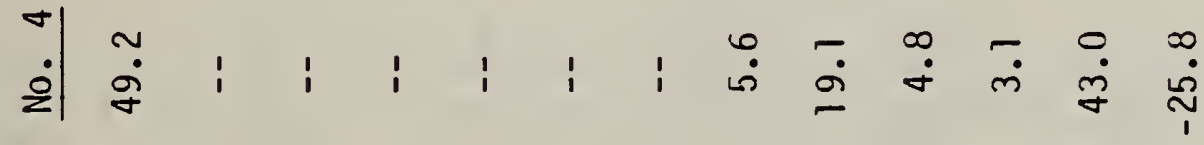

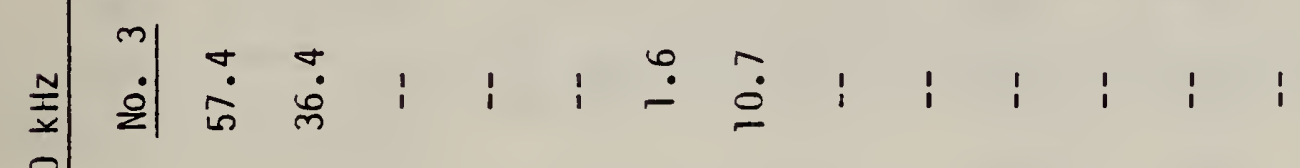

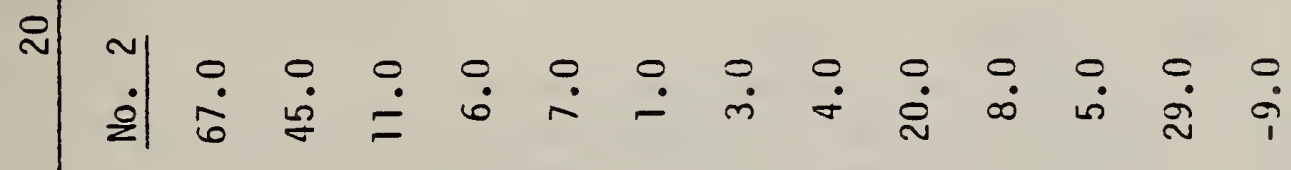

$\frac{9}{5}$

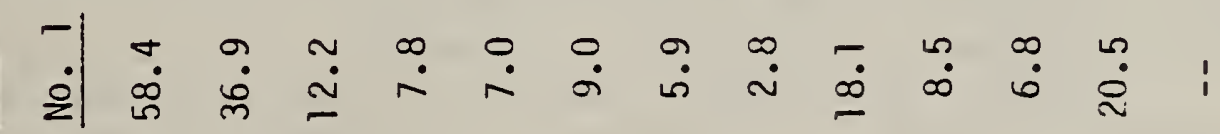

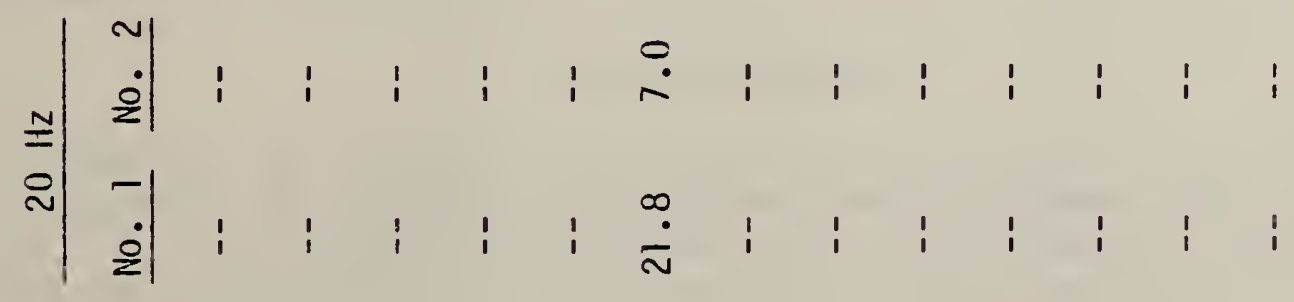

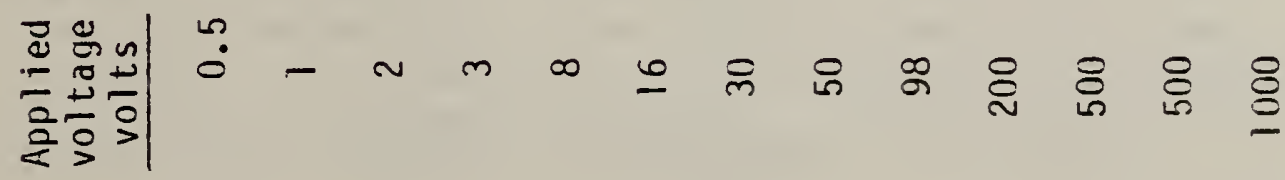

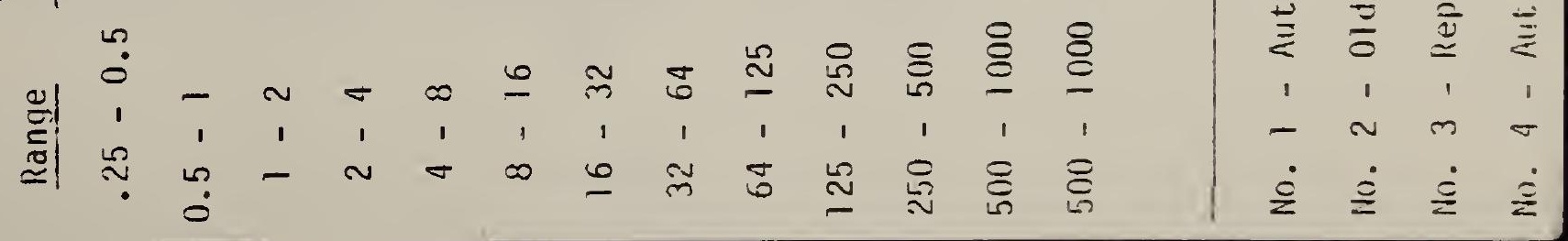




\section{Table 7. Range of ac/dc differences for transport standard (ppm)}

$\begin{array}{ccc}\begin{array}{c}\text { Voltage } \\ \text { range }\end{array} & & \begin{array}{c}\text { Test } \\ \text { voltage } \\ \text { volts }\end{array} \\ \begin{array}{c}0.25-0.5 \\ 0.5-1\end{array} & \begin{array}{c}0.5 \\ 1-2\end{array} & \begin{array}{l}1 \\ 1\end{array} \\ 2-4 & & 3 \\ 4-8 & & 8 \\ 8-16 & & 16 \\ 16-32 & 30 \\ 32-64 & 50 \\ 64-125 & 98 \\ 125-250 & 200 \\ 250-500 & 500 \\ 500-1000 & 500 \\ 500-1000 & 1000\end{array}$

\begin{tabular}{rrr}
\multicolumn{4}{c}{ Test } & Frequency & $(\mathrm{kHz})$ \\
$\frac{50}{18}$ & $\underline{50}$ & $\underline{100}$ \\
9 & 19 & 23 \\
1 & 2 & 4 \\
2 & 6 & 9 \\
0 & 0 & 0 \\
8 & 1 & 3 \\
8 & 15 & 3 \\
3 & 3 & 9 \\
2 & 6 & 10 \\
4 & 2 & 14 \\
4 & 50 & 39 \\
22 & 54 & 147 \\
17 & 70 & --
\end{tabular}


The test results show that at $20 \mathrm{kHz}$ the average value of the range of ac/dc differences for all voltages is only $8 \mathrm{ppm}$. At $50 \mathrm{kHz}$ the average value of the range is $19 \mathrm{ppm}$, and at $100 \mathrm{kHz}$, where skin effects and stray capacitance effects predominate, the largest range (at $500 \mathrm{~V}$ ) was $147 \mathrm{ppm}$. However, this large range is within the expected combined total uncertainty of $200 \mathrm{ppm}$ for the two systems. Even with this one range greater than $100 \mathrm{ppm}$, the average value of the range at $100 \mathrm{kHz}$ is still only $23 \mathrm{ppm}$. No intercomparison results were obtained at $1000 \mathrm{~V}$, $100 \mathrm{kHz}$, since the high-voltage-amplifiers in both systems could not supply sufficient power at that voltage-frequency combination.

Additional intercomparison tests were made using a single-range, coaxial type thermal voltage converter with large, but accurately known, ac/dc differences. The summary of the test results is shown in table 8. From the data, it is obvious that the two systems agreed well within the estimated total uncertainty limits. In fact, the data clearly show that the MIDAS-based system performed much better than had been anticipated when the project was undertaken.

As a final check of the system's performance, intercomparison tests were made using a single-range, coaxial type converter, which is used as a working standard for ac/dc testing at NBS. The results of these tests are summarized in table 9. Again, the results indicate excellent agreement between the two systems.

\section{CONCLUSIONS AND RECOMMENDATIONS}

The results of the work reported indicate that it is possible to measure ac/dc differences semiautomatically with uncertainties about the same as those obtained with manual testing techniques. The major advantage of the system appears to be the elimination of most of the tedium involved in manual testing, in which deflections of light beam galvanometers must be observed and recorded.

For future work, it appears that further improvements in system operation can be obtained by development of self-balancing TE comparators. Additionally, by taking advantage of improvements in digital voltmeter sensitivity, stability, linearity, and resolution, desktop computers, and system components whose operation is compatible with new digital/analog interfaces, it may be possible to develop improved ac/dc difference testing techniques.

\section{ACKNOWLEDGEMENTS}

The authors are indebted to C. B. Childers who made many of the tests, assembled the equipment, and helped the programmers test the software. E. S. Williams designed and built the low-thermal-noise and high-voltage switching modules, and provided some of the initial software which eventually became part of the total programming package. R. E. Kleimann, S. C. Bailey, and W. C. Caterisano each contributed portions to some of the computer programs. Thanks are also due B. A. Bell who provided helpful comments, encouragement, and support. 
Table 8. AC/DC difference for TVC "FA 50" (ppm)

\begin{tabular}{c|c|c|c|c}
\cline { 3 - 5 } $\begin{array}{c}\text { Applied } \\
\text { voltage }\end{array}$ & $\begin{array}{c}2 \\
\text { Frequency } \\
\mathrm{kHz}\end{array}$ & $\begin{array}{c}3 \\
\text { Manual }\end{array}$ & $\begin{array}{c}4 \\
\text { MIDAS }\end{array}$ & $\begin{array}{c}3-4 \\
\text { Difference }\end{array}$ \\
\hline 50 & 5 & 24 & 22 & 2 \\
\hline 50 & 10 & 52 & 50 & 2 \\
\hline 50 & 20 & 116 & 113 & 3 \\
\hline 50 & 50 & 308 & 305 & 3 \\
\hline
\end{tabular}

Table 9. AC/DC difference for TVC "FC 100" (ppm)

\begin{tabular}{c|c|c|c|c}
\multirow{2}{*}{$\begin{array}{c}\text { Applied } \\
\text { voltage }\end{array}$} & $\begin{array}{c}2 \\
\text { Frequency } \\
k H z\end{array}$ & $\begin{array}{c}3 \\
\text { Manual }\end{array}$ & $\begin{array}{c}4 \\
\text { MIDAS }\end{array}$ & $\begin{array}{c}3-4 \\
\text { Difference }\end{array}$ \\
\hline 100 & 20 & 3 & 5 & -2 \\
\hline 100 & 50 & 3 & 4 & -1 \\
\hline 100 & 100 & 13 & 18 & -5 \\
\hline
\end{tabular}




\section{REFERENCES}

[1] F. L. Hermach, E. W. Williams, Thermal Converters for AudioFrequency Voltage Measurement of High Accuracy, IEEE Trans. Instrum. Meas., Vol. IM-15, pp. 260-268, Dec. 1966.

[2] E. S. Williams, Thermal Voltage Converters and Comparator for Very Accurate AC Voltage Measurements, J. Res. Nat. Bur. Stand. (U.S.). 75C: 145-154, Dec. 1971.

[3] F. L. Hermach, AC-DC Comparators for Audio-Frequency Current and Voltage Measurements of High Accuracy, IEEE Trans. Instrum. Meas., Vol. IM-25, pp. 489-494, Dec. 1976.

[4] R. S. Turgel, A Comparator for Thermal AC-DC Transfer Standards, ISA Trans., Vol. 6, No. 4, pp. 286-292, 1967.

[5] C. H. Popenoe, M. S. Campbe11, MIDAS modular interactive data acquisition system - description and specifications, Nat. Bur. Stand. (U.S.), Tech. Note 790, Aug. 1973.

[6] Interface Between Data Terminal Equipment and Data Communication Equipment Employing Serial Binary Data Interchange, EIA RS-232-C. Electronic Ind. Assoc., 2001 Eye St., N.W., Washington, D.C. 20006 Aug. 1969.

[7] IEEE Standard Modular Instrumentation and Digital Interface System (CAMAC) - Computer Automated Measurement and Control, IEEE Stand. 583 - 1975, IEEE, 345 E. 47 Street, New York, NY 10017.

[8] American National Standard Code for Information Interchange, ANSI X3.4 - 1977, Amer. Nat. Stand. Inst., Inc., 1430 Broadway, New York, NY 10018.

[9] Ku, H. H., ed. Statistical Concepts and Procedures, Nat. Bur. Stand. (U.S.), Spec. Pub. 300; 1, Feb. 1969, 436 p.

[10] Natrella, M. G., Experimental Statistics, Nat. Bur. Stand. (U.S.), Handb. 91, Aug. 1963. 
Equipment lists, parts lists, and wiring diagrams of the equipment used in the NBS Semiautomatic AC/DC Thermal Voltage Converter Calibration System are contained in this appendix.

The use of trade names or company products does not constitute endorsement or recommendation by the National Bureau of Standards, and does not imply that the products named are necessarily the best available for the purpose.

1. List of Equipment.

1. Data Precision Model 5740 Frequency Meter.

2. Fluke Model $3330 B$ Programmable DC Voltage Standard.

3. Hewlett-Packard Model 745A AC Voltage Standard, option H18. ${ }^{1}$

4. Hewlett-Packard 746A High Voltage Amplifier.

5. Leeds \& Northrup Model 98290 Digital Linear Amplifier.

6. Guildline Model 9577 Digital Voltmeter with BCD interface.

7. Data Precision Model 175 Digital Multimeter (2 ea).

2. Parts list for High Voltage Switching Module.

1. D1-D4: IN5620 diodes.

2. Tl: Rectifier transformer. Universal Rectifier Corp., model RT201.

3. K1-K4: Relays. Magnecraft Electric Co., model W158HVXI, SPDT, DB-DM, 24 VDC. Rated $200 \mathrm{~mA}$ coil, $5 \mathrm{kV} \mathrm{dc}, 120 \Omega$ coil.

4. S1, S2: CTS Rotary switch, series 212, \#T205.

5. P1: Cable connector. Gen-Rad, type GR874-CA.

6. J1: Panel connector. Gen-Rad, type GR874-PBA.

IFor the frequency output connector of the ac calibrator, a triax BNC to regular BNC adaptor is required. The adaptor used was made by Trompeter Electronics, part number AD-PL76-EI-B1 20. 
7. Pilot light. Industrial Devices, 215 OAl.

8. J2-J4. BNC male panel mount connectors isolated from panel.

9. All resistors $1 / 4 \mathrm{~W}$.

3. Parts list for Low-Thermal-Noise Switching Module.

1. K1-K5: Solenoids. Guardian Electric Co., pull type $\frac{4}{\pi} 240 \mathrm{C}$. Coil voltage $24 \mathrm{~V}$ dc. $114 \Omega$ coil resistance.

2. Jl: Panel jack. Amphenol \#3102A receptacle, \#10S-02P insert.

3. P1: Cable plug. Amphenol \#3106B connector, \#10S-02p insert. \#AN3057 cable clamp.

4. J2-J9: BNC male panel mount connectors isolated from panel.

5. P2: Cable plug. Amphenol \#3106B plug, \#14S-05 insert, \#AN3057-6 cable clamp.

6. S1: C.T.S. rotary switch, series $212, \frac{\mu}{\pi} T 205$.

7. A11 L.E.D.'s red, 5V, $16 \mathrm{~mA}$.

4. Parts list for TE Comparator.

J1 \& J2: Panel jack. Amphenol \#3102A receptacle, \#10S-02P insert.

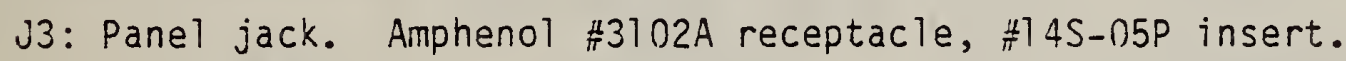

J4: Panel jack. Amphenol $\# 3102 \mathrm{~A}$ receptacle, $\frac{\mu 1}{\pi}$ OSL-03P insert.

Battery: Mallory Duracell RM42R $1.35 \mathrm{~V}$.

Meter: $0-1 \mathrm{~mA}, \mathrm{DC}$.

R1, R2: $10 \Omega$ Gen-Rad \#602-302.

R3: Beckman Helipot $\frac{u}{\pi} S A 4391,10$ turn, $100 \Omega, \pm 3 \%$.

(Lindeck potentiometer fine adjust).

R4: $750 \Omega, 10 \%, 1 / 2 \mathrm{~W}$, carbon.

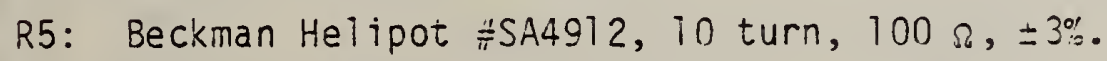

R5, R7: $100 \Omega, \pm 10 \%, 1 / 2$ W carbon.

R8, R9: 53k $\Omega, \pm 10 \%, 1 / 4 \mathrm{~N}$, carbon.

Rio, R11: $1 \Omega, \pm 1 / 2 \%, 1 \mathrm{~W}$, precision pie wound. 
R12: Precision pie wound, $1 \mathrm{k} \Omega, \pm 1 / 2 \%, 1 \mathrm{~W}$.

R13: Precision pie wound, $0.05 \Omega, \pm 1 / 2 \%, 1$ W.

R14: Beckman Helipot \#SA5427, 10 turn, $100 \Omega, \pm 3 \%$. (Kelvin-Varley divider fine adjustment).

R15: Gen-Rad $\frac{4}{\pi} 602-303,100 \Omega$.

S1: Leeds 3 Northrup 12 position, 2 pole rotary selector switch $\# 031262$. (Function switch).

S2: Leeds \& Northrup 12 position, 3 pole rotary selector switch :031263. (Kelvin-Varley divider coarse adjust).

S3: Leeds \& Northrup 12 position, 6 pole rotary selector switch $\frac{\mu}{\pi} 031266$. (E-high or E-low selector switch).

S4: SPST bat handle toggle switch.

S5, S6: Set and read detector sensitivity switches. Leeds \& Northrup SPST $\# 031187$.

57, S8: Set and read switches. Leeds \& Northrup Guarded Low Thermal Key switch DPST

S9: C.T.S. 7 position 2 pole rotary switch, series 212, \#T205. (Lindeck potentiometer coarse adjust). 


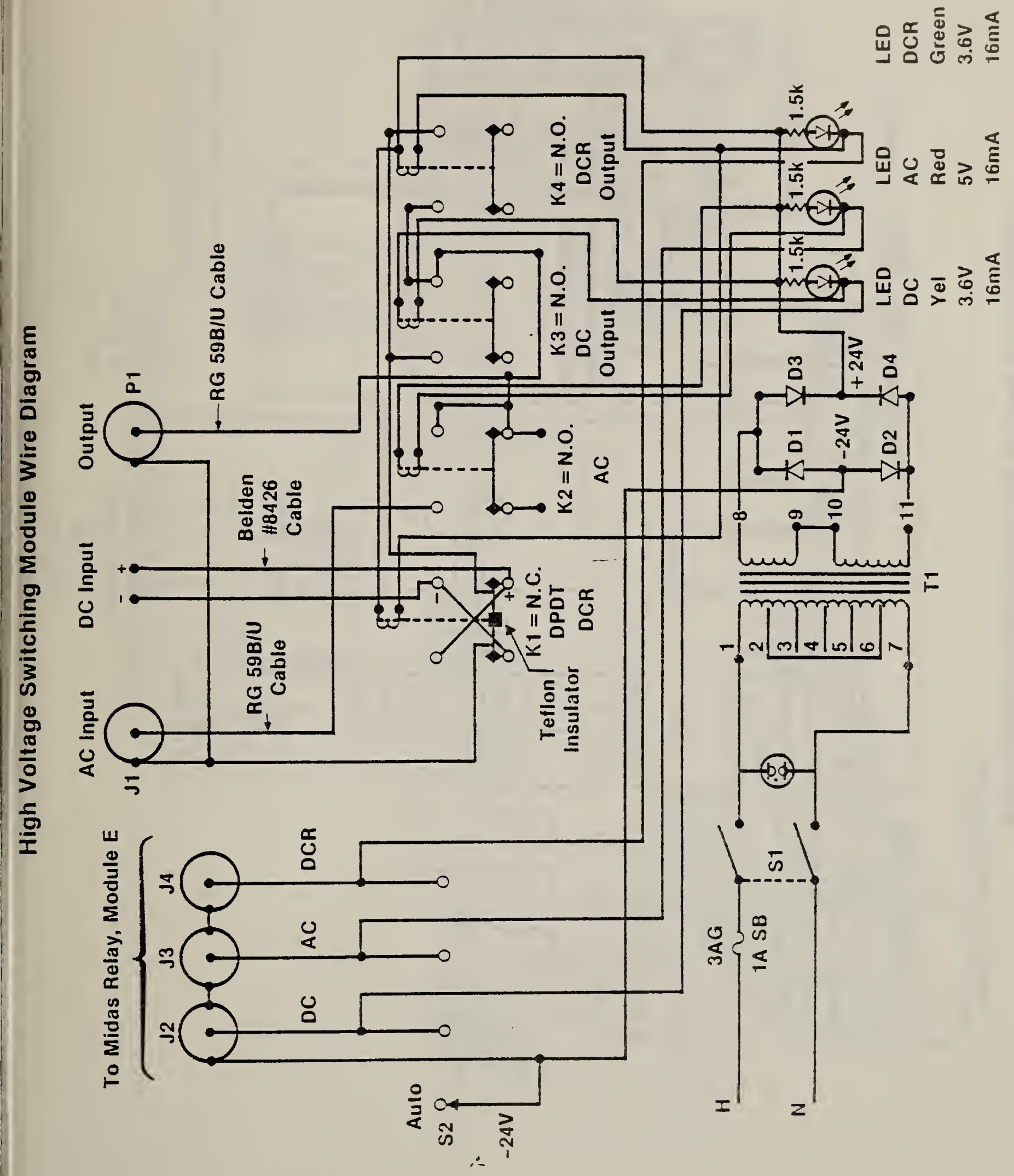




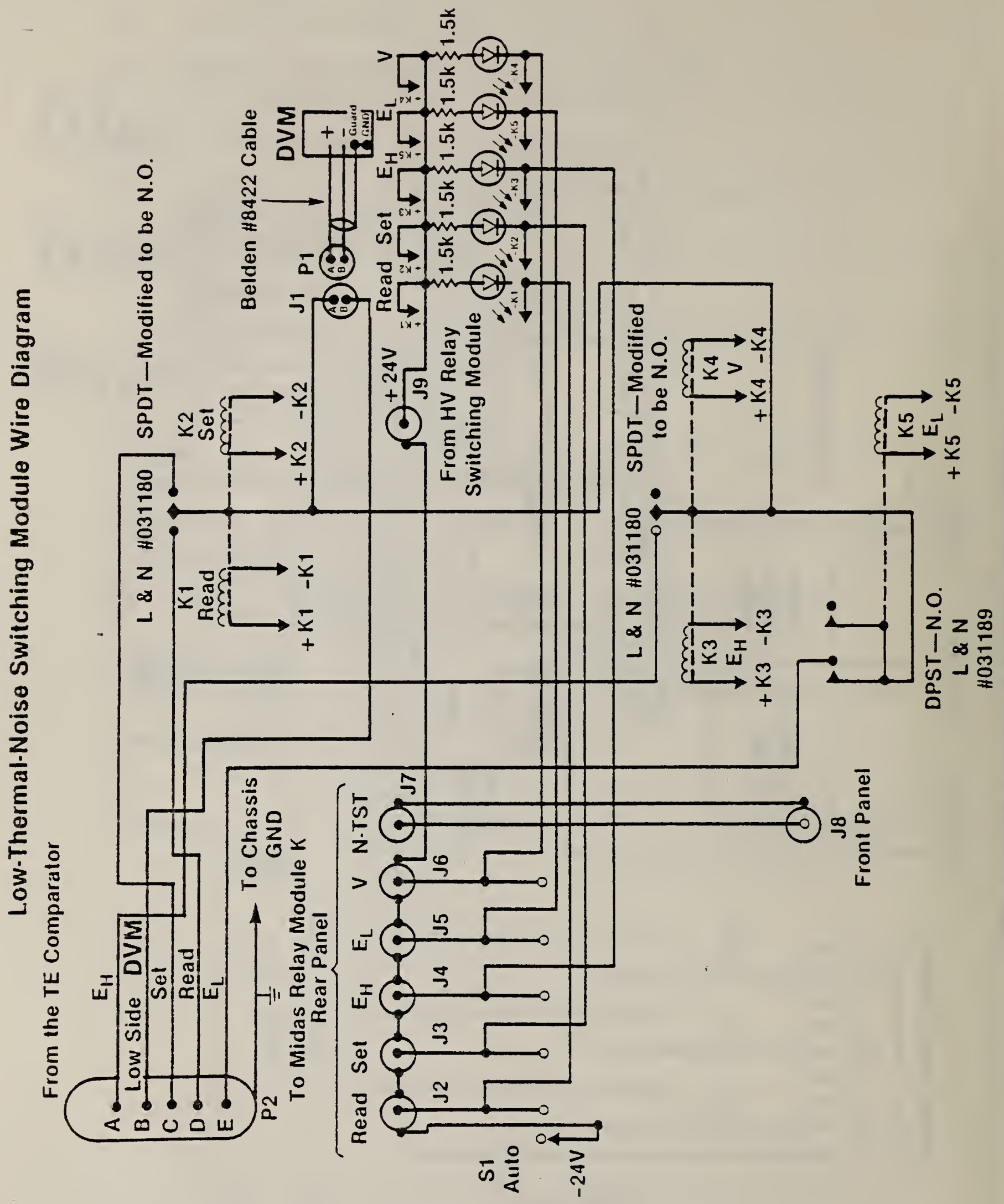




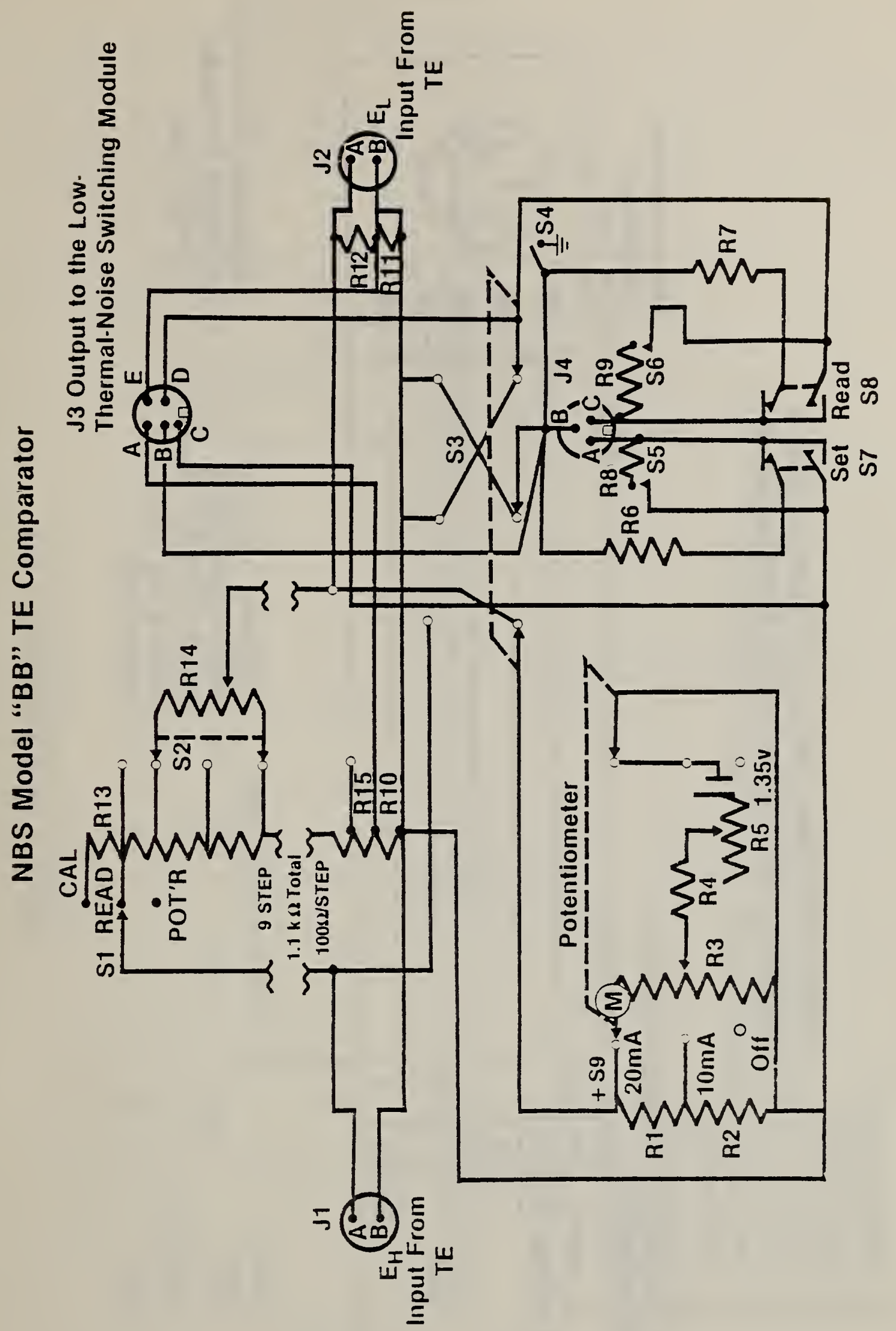



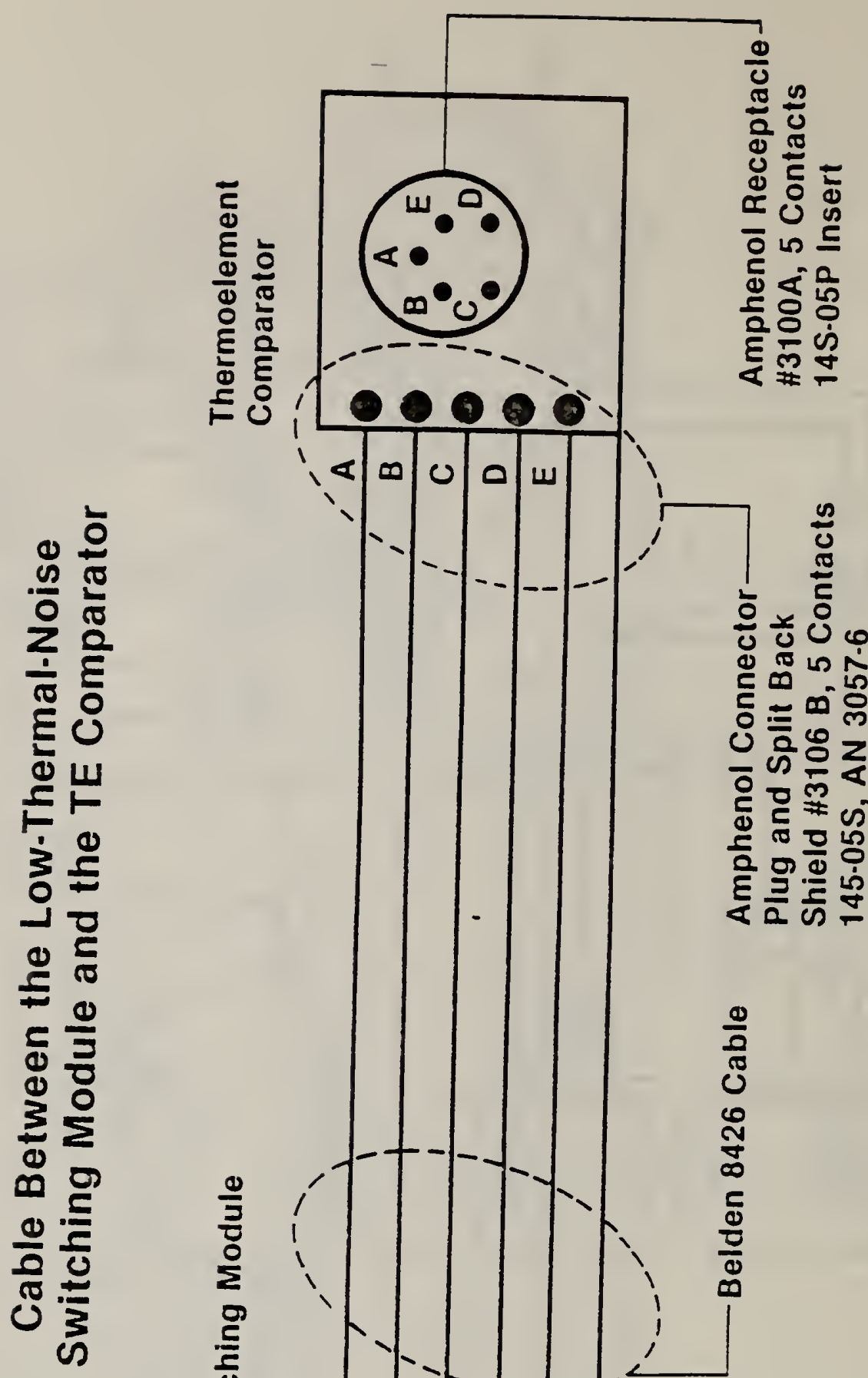


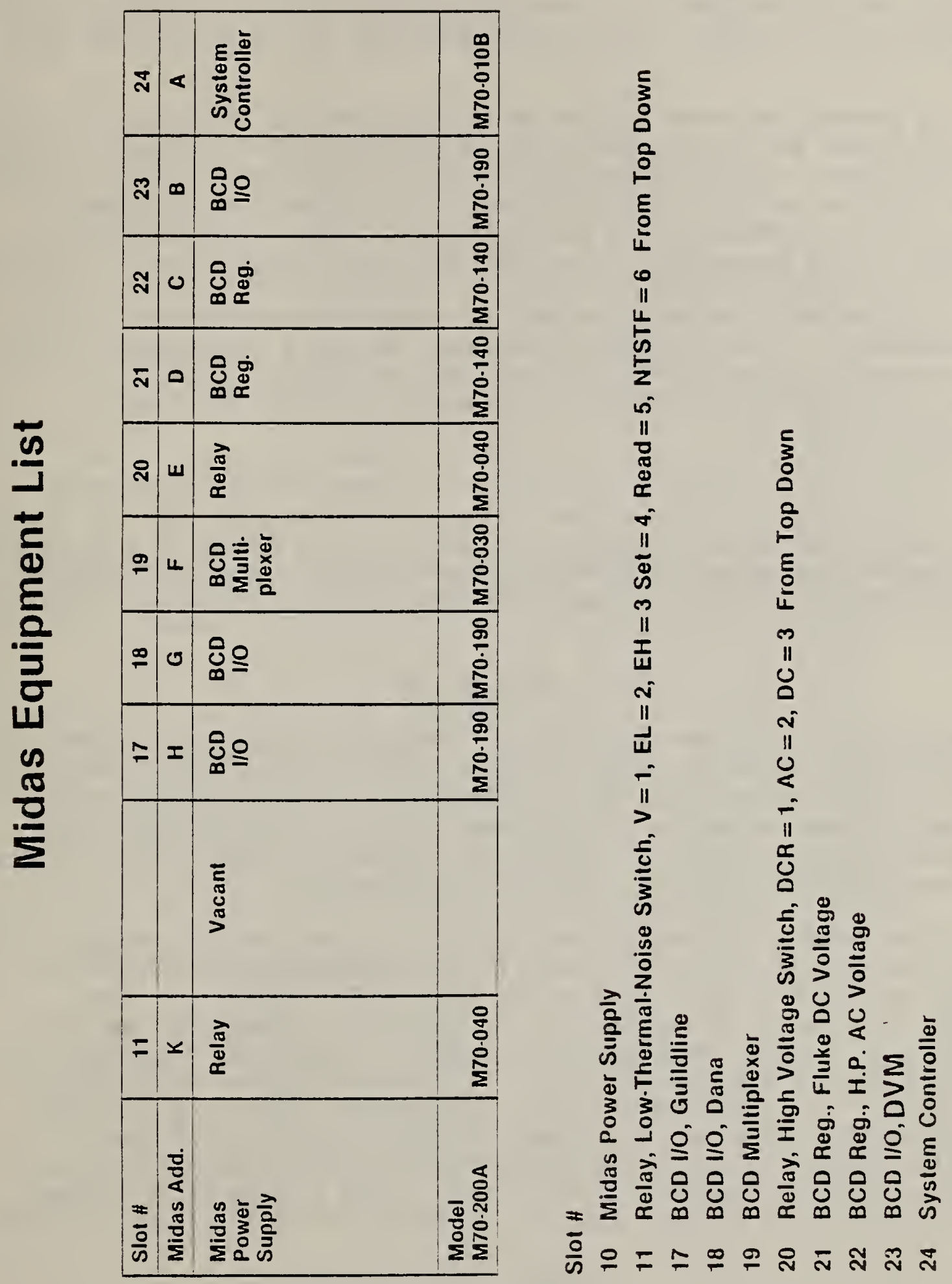




\section{ACDCHV Detailed Program Description and Program Listing}

For ease of understanding the following detailed narrative program description, the reader may find it useful to refer to the 1 ist of program variables on page 40 , and the program listing on page 44. Although not included in this report, a detailed program flow chart is available upon request.

The program begins by describing the software and appropriate reentry points, as well as system limitations which would result in over-voltages. Lines 20-108 are print statements which display the descriptive information and warnings on the CRT. Statement 109, in which the program shunts around a variable index (1ines 110-1020) and a data header (1 ines 1030-1170), is inserted when debugging, and deleted for formal testing when a heading is desired on the printed data sheet. In statements 1180-1280, string and array variables are dimensioned, and simple variables are initialized. The statements in lines 1290-1310 generate, through a read command and a series of data statements (1 ines 1320-1400), a library containing corrections to those TE standards that might be used during an ac/dc difference test.

The constants stored in data lines 1320-1390 are those which are used to calculate the value of the standard TE's dimensionless characteristic "n." Since $n$ varies with applied voltage, its value can be related to the TE's measured emf output, $E$ (in $\mathrm{mV}$ ). The value of $n$ is assumed to vary linearly with $E$. Thus, for example, for the standard "Fl" in line 1320 , $n$ is calculated as

$$
n=1.98-0.039 E
$$

String variables used for instructions to MIDAS are then dimensioned and defined (lines 1400-1420). Since instructions from, and data sent to, MIDAS are done in real time, delay statements are used to handle timing intervals between reception of programmed instructions and acquisition of data. An upper limit for these delay statements is defined in statement 1430 concluding the system's software initialization.

A series of linked subroutines comprise the body of the program which actually begins at line 1440. A print command causes the CRT to beep, prompting the operator to enter, via the CRT keyboard, a test voltage, test range, and standard TE range after a request for such test requirements has been displayed (1ine 1450). A conditional statement in line 1470 tests the status of flag $S$. S is set to 1 after an initial test so that for any succeeding tests, the program jumps to subroutines which turn off both $d c$ and ac voltages, restoring each set of test parameters when required (1ines 5970-6050 for dc, and 6060-6160 for ac). During a first run, however, $S$ equals zero so the program falls through, first to set the dc voltage, then to set the ac. 
Both voltage-setting routines follow similar general formats. Statements in lines $3430-3990$ set the ac voltage, while statements 4640-5190 set the dc. Before requesting voltage, range, and frequency (ac only) parameters, instructions for coding these parameters are displayed on the CRT. Any variables which may yet be necessary are then established. These include temporary variables (such as F18, R18, and $V 28$ in $a c$, and $R 2$ and $V 18$ in $d c$ ), all of which are used to store parameters when turning supplies on and off during high voltage tests. Any flags for branching around certain instructions when testing at high voltages are also included here; for example, $D$ in the ac routine (lines 3620-3650). Because the initial instructions to MIDAS differ, depending on a preselected range, conditional statements determine program flow to one of several sets of separate commands. Each of these command sets issues an initial instruction to MIDAS for a particular range before going back to the voltage set subroutine for more generalized instructions which send, through MIDAS, previously defined parameters. After MIDAS has sent the commands to those instruments being programmed, the operator is prompted, via the CRT, to check if each device has actually responded correctly. Should the operator indicate that a response is incorrect, the program recycles the subroutine to receive new instructions. If operator response indicates that the instruments have responded correctly, control is returned to statement 1520 of the main program.

After both dc (1500) and ac (1510) voltages have been set, instructions are displayed telling the operator to select the E-high comparator input, turn off the Lindeck potentiometer and the ground switch of the comparator and set the voltmeter to its $10 \mathrm{mV}$ range. A variable for the test number is incremented, while both "dc" and a low-thermal-noise (K2) relay are closed. The operation of the high voltage relays, as well as those solenoids contained in the low-thermal-noise switch module, is accomplished by instructions contained in repeatedly-accessed subroutines in lines 5690-5900. Next, the dc power supply is turned on to the previously programmed voltage value $(1610)$. Before the voltmeter is read (1640), the program executes a time delay (1620-1630) to permit the TE to reach thermal equilibrium. Statements 1641-1651 ask which standard TE is being used and check through a data library for its correction. This correction is used in each of two formulas, only one of which is accessed, contingent upon whether the standard or the UUT is connected to the E-high or E-low input of the comparator (1750-1770).

When $E_{S}>E_{t}$ the program variable $K$ is computed as

$$
K=E_{t} n_{s}=E_{t}\left(M_{s}-N_{s} E_{s}\right)
$$

and, when $E_{t}>E_{S}, K$ is computed as

$$
K=E_{S} n_{S}=E_{S}\left(M_{S}-N_{S} E_{S}\right)
$$

where the subscripts $t$ or s refer to the UUT or the standard TE, respectively, and $M$ and $N$ are constants as defined in the program 
variable list on page 40 . These equations have been derived in [2]. The emf of the TE connected to the E-high input is read first by the voltmeter, and its value displayed on the CRT. Should E-low have a greater emf output than the TE connected to the comparator's E-high input, the operator is instructed to switch comparator connections, the test is aborted (1655-1718), and the initialization process begun again. If the standard and test TE's are properly connected to the comparator, $K$ is computed and printed on the data sheet along with voltage, test range, standard TE range, and emf outputs for both the standard and the UUT.

If the UUT's emf actually is E-high, the operator is prompted to select the E-high input of the TE comparator (if E-test < E-high, the input selector switch remains at the E-low position). The potentiometer is turned on, the $10 \mu \mathrm{V}$ range of the voltmeter selected, and the potentiometer adjusted until the voltmeter indicates within $\pm 500 \mathrm{nV}$. Instructions and prompts in the statements in lines 1830-1950 cue the operator to execute these manual operations. Then relay $K 2$ opens and relay $\mathrm{Kl}$ closes (lines 1970-1990). The operator is then instructed to adjust the Kelvin-Varley voltage divider $( \pm 100 \mathrm{nV})$, after which $\mathrm{dc}$ voltage parameters are stored, and the de standard turned off. Both "dc" and $\mathrm{Kl}$ relays open now, while relay $\mathrm{K} 2$ closes. Column headings for the data sheet are printed, and variables for statistical calculation are initialized.

Appropriate frequency corrections are computed for the standard TE. Statements 2220-2230 prompt the operator to define the test frequency, and statements 2240-2320 use this frequency value to determine the correction and truncate the computed correction to a whole number. Now the "dc" relay closes, and the dc power supply is turned on to the previously selected test voltage, at which point the $k 2$ relay closes. The operator is then directed to readjust the potentiometer, after which the dc voltage and range values are stored, the power supply turned off, and the "dc" relay opened. Then the "ac" relay closes and the ac power supply is turned on, first at 105 volts and finally to the proper high voltage. A time delay in lines $2480-2490$ allows the ac supply to settle and the TE to reach thermal equilibrium before transferring control to an ac voltage check subroutine $(4000-4630)$ that adjusts the ac voltage so that the output of the test TE is within 1000 nanovolts of its output with dc voltage applied. The subroutine branches, depending upon whether the ac voltage is too high or too low. The ac voltage is adjusted to provide nominally equal UUT output only with direct dc voltage applied, and not when reversed $d c$ is applied. Furthermore, this ac voltage adjustment is made only once at the beginning of the measurement sequence to obtain four determinations of ac/dc difference. Hence, it is possible, for UUT's with large dc reversal differences, for second-order errors to become significant. However, the multirange instrument and single range thermal converters tested with this system did not possess large dc reversal differences.

The system was intended to calibrate high-quality thermal converters. Hence, additional balancing steps to eliminate uncertainties due to large dc reversal difference ( $i . e$. , difference between the dc direct and 
reverse voltages required for the same TE emf output of the UUT) were not needed. For the worst case, using 2.0 and 1.6 as the two extremes of the characteristic $n$ which may occur for the standard and UUT TE's, it can be shown [4] that systematic uncertainties of less than one-fourth the UUT's dc reversal difference will occur. Minor software changes can eliminate this systematic error if large reversal voltages are anticipated. The changes would amount to adjusting the ac voltage for a TE output equal to that when de reversed voltage is applied to the test circuit. The only penalty for such a change in the operating procedure would be an increase in testing time of perhaps one or two minutes (for four determinations of ac/dc difference).

There is also the possibility of a systematic uncertainty if the ac or dc voltage standards drift during a sequence of four determinations. However, for the same extremes of $n$, the uncertainty is only 10 ppin either source drifts by as much as $100 \mathrm{ppm}$. The STABLV and STABHV programs readily provide information about the stabilities of the sources.

Once the ac voltage has been adjusted for about equal TE output as when $\mathrm{dc}$ is applied, relay $\mathrm{K} 2$ opens and relay $\mathrm{Kl}$ closes (2510-2540). Cautions are displayed on the CRT to allow the voltmeter to stop drifting before rebalancing the divider, should that be necessary. Statements in lines 2600-2610 generate a time delay before the program jumps to test the 10 voltmeter readings $(5500-5650)$ to determine if the standard deviation of an observation of 10 readings is $<200 \mathrm{nV}$. The test routine allows for up to five reading sequences to be obtained before the test is aborted and a suitable warning displayed on the CRT.

AC/DC difference is reported on the basis of the average of four determinations. Each determination is calculated from the voltage measurements with ac, $\mathrm{dc}+, \mathrm{dc}-$, and ac voltages applied simultaneously in this sequence to the standard and test TE's. The last ac reading of one determination becomes the first ac reading of the next determination. Each reading is taken by closing the appropriate relays, bringing up the power supplies to previously programmed values, displaying the reading in nanovolts, then storing the voltage parameters, powering down, and opening the relays. This measurement process is accomplished by means of statements in lines 2650-3050 and concludes the midsection of the program.

The final section of the program computes statistical parameters, formats the final output, generates a copy of the test data, and provides measurement options to the operator. Statements 3060-3130 calculate the mean of the four determinations and the standard deviation of an obseryation in pom, while statements 3140-3150 format the printed data, and the statement in line 3160 causes the data to be printed. Should the operator wish to run another test, variables used to determine a pooled standard deviation are then incremented in lines 3170-3230. Finally, options are displayed (3240-3250) asking whether to repeat a test with or witnout averaging, to change parameters, or to terminate. Since ac was the last measurement to be taken, its voitage is turned off, although the ac 
parameters are automatically stored for potential reruns (3275).

Statements 3280-3350 transfer program control to the operator-selected option. If the operator has chosen to repeat a test without averaging, lines 3380-3410 delete the pooled standard deviation data.

The standard deviation of an observation printed on the data sheet is calculated for the four determinations of $a c / d c$ difference at a fixed voltage and frequency from the following:

(Standard deviation $)^{2}=($ Variance $)$, and the

$$
\text { Variance }=\frac{\sum_{i=1}^{n_{k}}\left(x_{i}-\bar{x}\right)^{2}}{n_{k}-1} \text {, }
$$

$$
\sum^{n_{k}} x_{i}
$$

where, $\bar{x}=\frac{i=1}{n_{k}}$, and $n_{k}$ is the number of determinations at a fixed voltage and frequency; i.e., the number of readings in test $k=n_{k}$.

The final statistics which are printed on the data sheet are calculated using the variables

$$
\begin{aligned}
H= & \text { total number of readings, } \\
L= & \text { Number of independent tests, } \\
D 1= & \text { Degrees of freedom }=H-L, \\
S 2= & \text { Pooled estimate of the test standard deviation of } \\
& \text { the mean } \equiv \text { standard deviation of the test (SDT). }
\end{aligned}
$$


An estimate of the total random uncertainty is calculated as three times the SDT and this product is therefore an estimate of the average 30 value for the test, and is calculated as

$$
3 \sigma=3\left\{\frac{\sum_{k=1}^{t}\left[\sum_{i=1}^{n_{k}}\left(x_{i}-\bar{x}\right)^{2}\right]}{(n-t)(n / t)}\right\}^{1 / 2},
$$

where, the degrees of freedom $=n-t$, total number of readings $=n=\sum_{k=1} n_{k}$, number of independent tests $=t$. These concepts are discussed fully in [9], pp. 316, ff. 
Note: $\emptyset=$ zero and not letter "oh"

Variable

Name

Definition

A

$A D$

A2

A4

A5

A6

B

$B D$

B1

$B \$$

C

C7

C\$

$\cos$

D

DI

D\$
Voltage applied to test and standard TE.

Array used to store the four determinations of ac/dc difference.

Variable in the subroutine used to increase or decrease the ac voltage when driving the UUT's output to within $1000 \mathrm{nV}$ of its value with de voltage applied.

Variable which is input by the operator after verifying the dc voltage ( $\theta$ or 1 ).

Variable which is input by the operator after verifying the ac voltage and frequency ( $\delta$ or 1 ).

Variable which is input by the operator after determining whether or not to change the frequency after the ac voltage is set.

Voltage range of test TE.

Average of all determinations at one voltage and frequency.

Average of the four latest determinations of the test. 81 is used in the computation of the standard deviation of the test.

Array used to store the data related to a particular TE.

Frequency correction to standard TE which is calculated by using test frequency $(P)$.

Variable used to increment or decrement the ac voltage to drive the UUT's output to within $1000 \mathrm{nV}$ of its value with direct dc applied.

String containing name of standard TE.

Variable used in input string to dc source to set range, polarity, remote trip, and voltage trip range.

Flag to initially turn on ac supply at $105 \mathrm{~V}$, and then return and set the correct voltage and range.

Variable used for degrees of freedom in statistical

calculations. $\mathrm{DI}=\mathrm{H}-\mathrm{L}$.

String used to input date. 
Variable

Name

E

E9

$E 7-E 4$

FD\$

F1\$

G

H

I

I $\varnothing$

IS

I8

I9

J

31

K

$K D$

Definition

E-high voltage reading, in $\mathrm{mV}$.

E-low voltage reading, in $\mathrm{mV}$.

DLA voltage difference readings with $a c$, $+d c,-d c$, and $a c$ voltages applied to the standard and UUT TE's.

Used to input frequency to the ac source.

Storage variable for the ac source frequency used in the ac voltage setting routine.

Dummy variable.

Total number of determinations of ac/dc difference per test run.

Variable defining a for/next loop in which the standard TE code file is established.

Variable used to designate the first element in array $A$ (the test voltage) when defining the variables $M$ and $N$. Also used to define $E l=$ near-null voltage reading with ac applied, $E 2=$ reading with $+d c, E 3=$ reading with $-d c$, $E 4$ = reading with $a$ C.

String used to input the test instrument manufacturer, name, and model number.

Variable used to define the for/next time interval 10op.

Variable used to define the for/next "wait" timing loop; e.g., to allow the dc or ac supplies to settle, or to allow time for a TE to reach thermal equilibrium.

Flag for abort and total reset.

Variabie used to define for/next loop in which $x 6$ is computed. $\mathrm{Jl}$ is used in the pooled estimate of the test standard deviation of the mean.

Result of the standard TE's emf multiplied by the TE characteristic $n_{S}$ when $E_{S}<E_{t}$, or the test TE's emf times $n_{s}$ when $E_{s}>E_{t}$.

Variable used to define a for/next loop in which the ten DLA near-null voltage readings are obtained, and then calculate the standard deviation of the ten readings. 
Variable

Name

$L$

M

MD

RI

$R 2 \$$

ROS

$R S$

RIS

S

ST

S2

T

$T \emptyset$

T\$

VS

vos

VI\$

125

V

\section{Definition}

Number of independent tests for a complete test run; i.e., for all voltages and frequencies.

One of two constants used in the calculation of $\mathrm{n}_{\mathrm{s}}$. The other constant is $N$.

Variable used to implement MIDAS calls. MO is the computer's PASLA channel number in decimal.

Variable used to set the range of the dc supply.

Variable used to store the range of the dc supply before turning it off.

Variable used to select the range for the ac supply.

Character string reference used for relay operation.

Variable used to store the range of the ac supply before turning it off.

Flag for initial dc and ac voltage ranges.

Standard deviation of an observation for four or more determinations of ac/dc difference at one voltage and frequency.

Pooled estimate of the test standard deviation of the mean. Decision point variable.

Time delay variable.

Output format string.

MIDAS input string.

String used to set voltages on both ac and dc supplies.

Variable used to store the dc voltage value in the dc voltage setting routine.

Variable used to store the ac voltage value in the ac voltage setting routine.

Numeric value of VS. $V$ is the value of the voltage reading. 

Variable
Name

W

$X, X 1, \times 2$

$\times 5, \times 6, \times 7$

Y

Y1

Z

\section{Definition}

Divisor used in the calculation of the mean of four or more determinations at one voltage and frequency.

All used in the standard deviation of the test (SDT). calculation.

Used in calculating the pooled estimate of the standard deviation of the mean.

Intermediate variable used in calculating $Y$ l.

Standard deviation of ten voltmeter readings.

Counter in the five standard deviation abort subroutine. 


\section{ACDCHV PROGRAM LISTING}

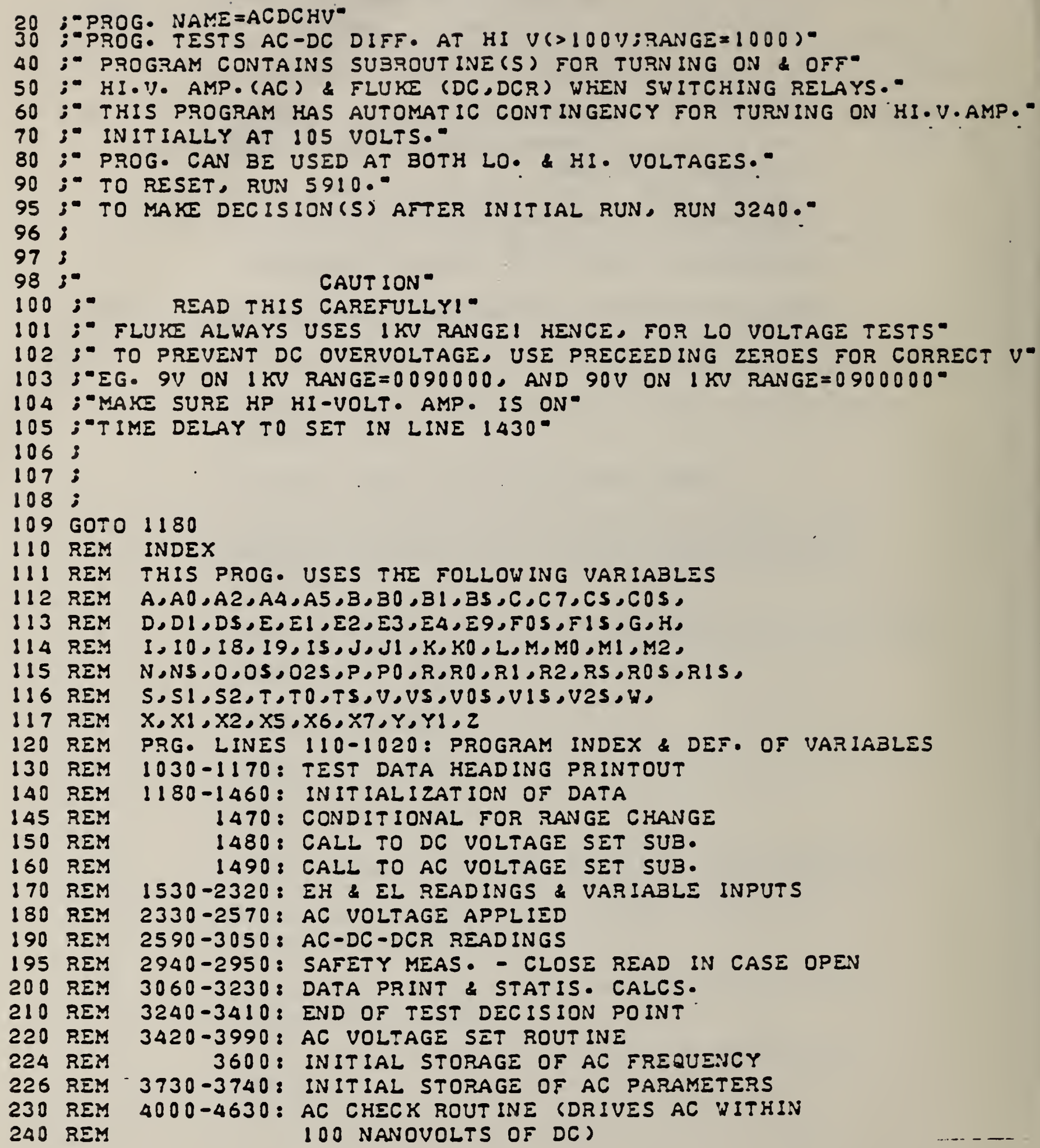


24I REM 242 REM 243 REM 250 REM 255 REM 260 REM 270 REM 280 REM 290 REM 300 REM 310 REM 312 REM 314 REM 316 REM 318 REM 320 REM 330 REM 340 REM 350 REM 360 REM 370 REM 380 REM 390 REM $\triangle 00$ REM 410 REM $\triangle 20$ REM $\triangle 30$ REM 440 REM 450 REM 460 REM $\triangle 70$ REM 480 REM $\triangle 90$ REM 500 REM 510 REM 520 REM 530 REM

540 REM 550 REM 560 REM 570 REM 580 REM 590 REM 600 REM 610 REM 612 REM 614 REM 616 REM 618 REM 620 REM 630 REM 631 REM 640 REM 650 REM 651 REM 660 REM 661 REM
NOTE; TO CHANGE NULL RANGE = LINE 4080 TO CHANGE INCREMENT - LINES 4150 \& 400 FOR L.V. FOR H.V. INCREMENT - LINES $4170 \& 4420$

4640-5190: DC VOLTAGE SET ROUTINE $4760-4770$ : INITIAL STORAGE OF DC PARAMETERS 5200-5390: STATIS. PRINT ROUTINE FOR POOLED S.D. 5400-5490: DLA READ ROUTINE 5500-5680 \& STD. DEV. TEST (OF DLA READINGS ) 5690-5790: E-MOD. RELAY SET ROUTINE (HI. V. SW.) 5800-5900: K-MOD: RELAY SET ROUT INE (LO: THER. "SW.) 5910-6640: RESET; TURN-OFF \& TURN-ON SUSROUTINE 5950-6050: TURN-OFF FLUKE \& REDEFINE DC PARAM. 6060-6160: TURN-OFF HI.V.AMP. \& REDEFINE AC FARAM. 6170-6330: TURN-ON FLUKE \& RESTORE DC PARAM. 6340-6630: TURN-ON HI.V.AMP. \& RESTORE DC PARAK.

RUN 3360 : TO CHANGE RANGE

1510: TO CHANGE FREQUENCY $2330:$ TO REPEAT TEST

3290: TO RESET RELAYS ONLY 3380 : TO TO REPEAT W/O AVE.

$5200:$ TO GET POOLED S.D. STATIS. PRINTOUT

5910: TO ABORT \& RESET ALL RELAYS $A=$ VOLTAGE APPLIED TO STANDARD TE. AO =ARRAY USED TO STORE THE 4 DETERMINATIONS . A2 = INCREMENTED IN AC VOLTAGE CHECK ROUTINE $B=$ RANGE OF TEST TE $B O=A V E$. OF ALL RDGS OF A PART ICULAR TEST. Bl=AUE: OF ONLY 4 LATEST READINGS • BS =ARRAY USED TO STORE EACH TE'S CONSTANTS . C=STD. TE FREQ. CORR - DETERMINED FROM INPUT FREQ =P CT=VOLTAGE INCREMENT IN AC BALANCE ROUT.

CS = STRING CONTAINING I.D. OF STD. TE

COS=USED IN INPUT STRING TO DC SOURCE D=COUNTER FOR INITIAL INPUT ( $105 \mathrm{~V}$ ) FOR HI.V.AMP. (AC) DI I DEGREES OF FREEDOM=H-L DS= STRING USED TO INPUT DATE

$E=E-H I G H$ MILLIVOLT READING (EH) $E 9=E-L O W$ MILLIVOLT READING (EL)

EI TO E4=ALTERNATING AC-DC-DCR-AC NULL READINGS FOS=USED TO INPUT FREQ. TO AC SOURCE G=DUMMY VARIABLE

H=TOTAL NO. OF DETERMINATIONS PER RUN

IS=STRING USED TO INPUT TEST INSTRUMENT MEG \& MODEL NO. $J=$ COUNTER FOR ABORT \& TOTAL RESET

$K=P R O D U C T$ RESULT OF STD. EMF*STD.

TE CHARACTERISTIC (N, LOWER CASES

WHEN ES ET

OR TEST EMF*STD TE CHARACTERISTIC

(N, LOWER CASE) WHEN ESDET

$L=T O T A L$ NO. OF TESTS PER RUN

$M=$ CONSTANT USED TO DETERMINE STD. TE

CHARACTERISTIC N-SUBSCRIPT $S$ (N, LOWER CASE)

$M O=I N$ MIDAS CALL IS THE PASLA CHANNEL NO. IN DEC. $M I=M A X$. LENGTH OR TERMINAT ING CHAR. OF HIDAS INPUT STRING

M2=STATUS VARIABLE SET AFTER EACH MIDAS CALL 
680 REM NSESTRING USED TO INPUT OPERATOR'S NAME

690 REM OSEINPUT STRING SPECIFYING PHYSICAL ADDRESS

700 REM O2S = STRING USED TO INPUT TEST NO.

710 REM PAFREQUENCY INPUT (KOHZ)

720 REM R=RANGE OF STD. TE

730 REM RO=UARIABLE SELECTS RELAY OPERATION

740 REM HV RELAYS. E-MODULE. RO= 1 . CLOSE DCR RELAY

750 REM RO=2 - CLOSE AC RELAY

760 REM RO=3: CLOSE DC RELAY

770 REM RO=15: OPEN DCR RELAY

780 REM RO=12:\%OPEN AC RELAY

790 REM RO=130:OPEN DC RELAY

800 REM

810 REM

820 REM

830 REM

840 REM

850 REM

860 REM

870 REM

880 REM

890 REM

900 REM

901 REM

910 REM

920 REM

930 REM

940 REM

950 REM

960 REM

961 REM

970 REM

980 REM

990 REM

1000 REM

K-MODULE. RO=3, CLOSE EH. RO=2, CLOSE EL RELAY. RO=4 . CLOSE SET RELAY

$R O=5 \because$ CLOSE READ RELAY

$R O=13$; OPEN EH. RO=12, OPEN EL RELAY.

$R O=14 . . O P E N$ SET RELAY

$R O=15 \because O P E N$ READ RELAY

$R O=0 . \because$ OPEN ALL RELAYS

ROS = RANGE SELECT FOR AC SOURCE

RS =CHARACTER STRING REFERENCE USED FOR RELAY OPERATION $S=$ COUNTER FOR RANGE

SI=STD. DEV. OF AN OBS . FOR

$\triangle$ OR MORE DETERMINATIONS

S2 POOLED EST. OF TEST S.D. OF MEAN

$T=D E C I S I O N$ POINT VARIABLE

TO=TIME DELAY LOOP VARIABLE

TS =OUTPUT FORMAT

US =STRING OUTPUT FROM MIDAS

UOS=STRING INPUT TO SET VOLTAGE

ON BOTH AC \& DC SOURCES

$V=N U M E R I C$ VALUE OF US

$Y=D I V I S O R$ IN AUE. CALC .

$X, X 1, X 2, X 5, X 6, X 7=A L L$ USED IN S.D.T.

$Y=U S E D$ IN $Y 1$ CALC.

1010 REM $Y 1=S T D$. DEV. OF 10 DLA READINGS

1020 REM $Z=C O U N T E R$ OF YI 'S $Z=5=A B O R T$

1030 DIM OLS $(6)$, IS $(20)$, DS $(15)$, NS $(25)$

1040 ; INPUT CURRENT DATE, YOUR NAME,TEST NO.: ,AND TSST INST.:

1050 3⿻

1060 INPUT DS,NS, 025, IS

1070, ON (6)-DATE.......... DS

$1080 ;$ ON $(6)$

$1090 ;$ ON $(6)$ OBSERUER..............................

$1100 ;$ ON (6)

1110, ON $(6)=$ TEST NO................................

$1120 ;$ ON (6)

1130 , ON $(6) \cdots$ INST................................ IS

$1140 ;$ ON (6)

1150, ON (6)

1160, ON $(6)=$

1170, ON $(6) \cdots$

APP TEST STANDARD

$V$ RANGE TE RANGE
ES ET

MU MV

1180 DIM FOS (2), F15 (2),ROS (1),R1S (1), VOS $(7)$, V1S $(7)$, V2S $(7)$

1190 DIM COS $(3), \operatorname{Cs}(2), \operatorname{TS}(72), 35(7,8), A(8,2)$ 


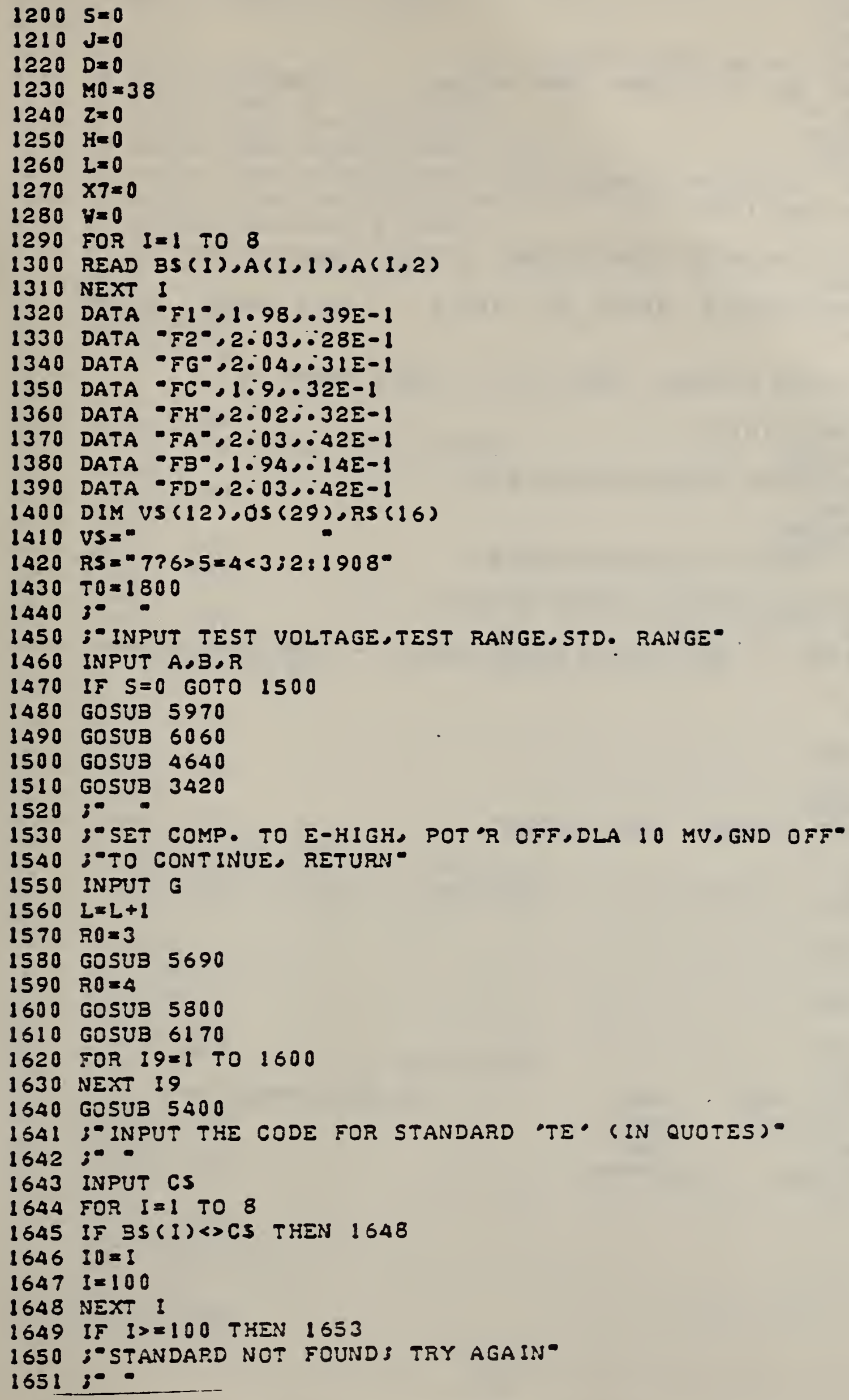


1652 GOTO 1641

$1653 M=A(10,1)$

$1654 N=A(10,2)$

$1655 E=U * 1000$

$1660 ;-E-H I G H \quad-\because,-M I L L I V O L T S^{\circ}$

$16703^{\circ C H A N G E ~ ' B B ' ~ T O ~ E-L O Y, ~ T H E N ~ R E T U R N ~ * ~}$

1680 INPUT G

1690 GOSUB 5400

$1700 \quad E 9=V * 1000$

$1710 ;-E-L O W=*, E 9,-M I L L I V O L T S^{\circ}$

1712 IF E>E9 THEN 1720

$17143^{\circ}$

1716 ; $E-L O W ~ I S ~ G R E A T E R$ THAN E-HIGH, SWITCH CONNECTIONS*

1718 GOTO 5910

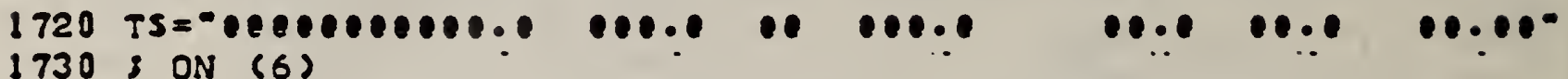

$1740,3^{\circ}-$

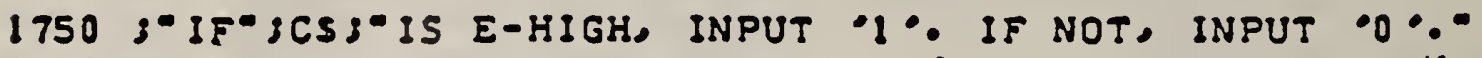

1760 INPUT G

1770 IF $G=0$ GOTO 1810

$1780 K=E 9 *(M-E * N)$

$1790 ;$ ON (6) USING TS,A,B,CS,R,E,E9,K

1800 GOTO 1940

$1810 K=E 9 *(M-E 9 * N)$

$1820 ;$ ON (6) USING TS,A,B,CS,R,E9,E,K

$1830, \cdots$

1840 ; SET COMPARATOR TO E-HIGH. RETURN *

1850 INPUT $G$

$1940 ;$ "POT R ON - SET DLA 10 MICRO-VOLTS - SET NULLORETURN*

$19503^{\circ}$

1960 INPUT G

$1970 R O=14$

1980 GOSUB 5800

$1990 R O=5$

2000 GOSUB 5800

$2010 ; " B A L A N C E$ DIUIDER, THEN RETURN"

2020 3*.

2030 INPUT $G$

2035 GOSUB 5970

$2040 \quad 80=15$

2050 GOSU3 5800

$2060 \quad R .0=13$

2070 GOSUB 5690

$2080 \quad R D=4$

2090 GOSUB 5800

$2110 ;$ ON (6)

2120 ; ON (6) $\mathrm{KIZZ}$ COR

2130 ; ON (6) 5 STD AUE T*

$2140 ;$ ON (6)" PPM

$2150 ;$ ON (6)"DEV COR PPM"

AC-DC DIFFERENCE

$2160 ;$ ON (6)

$2170 \quad x=0$

$2180 \quad x 1=0$

$2190 \times 2=0$

$2200 \quad C=0$

$2210 \quad Y=0$ 


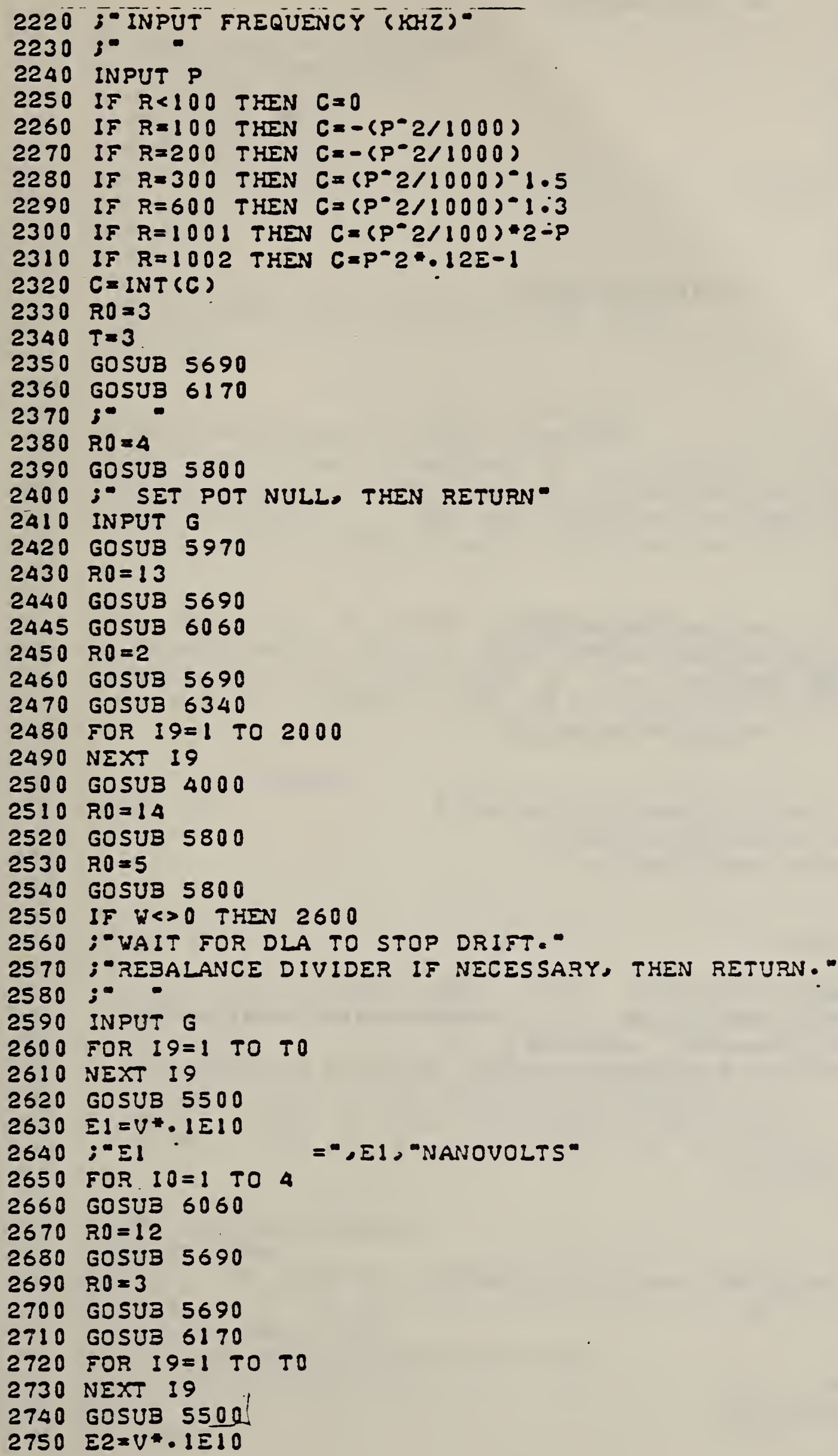




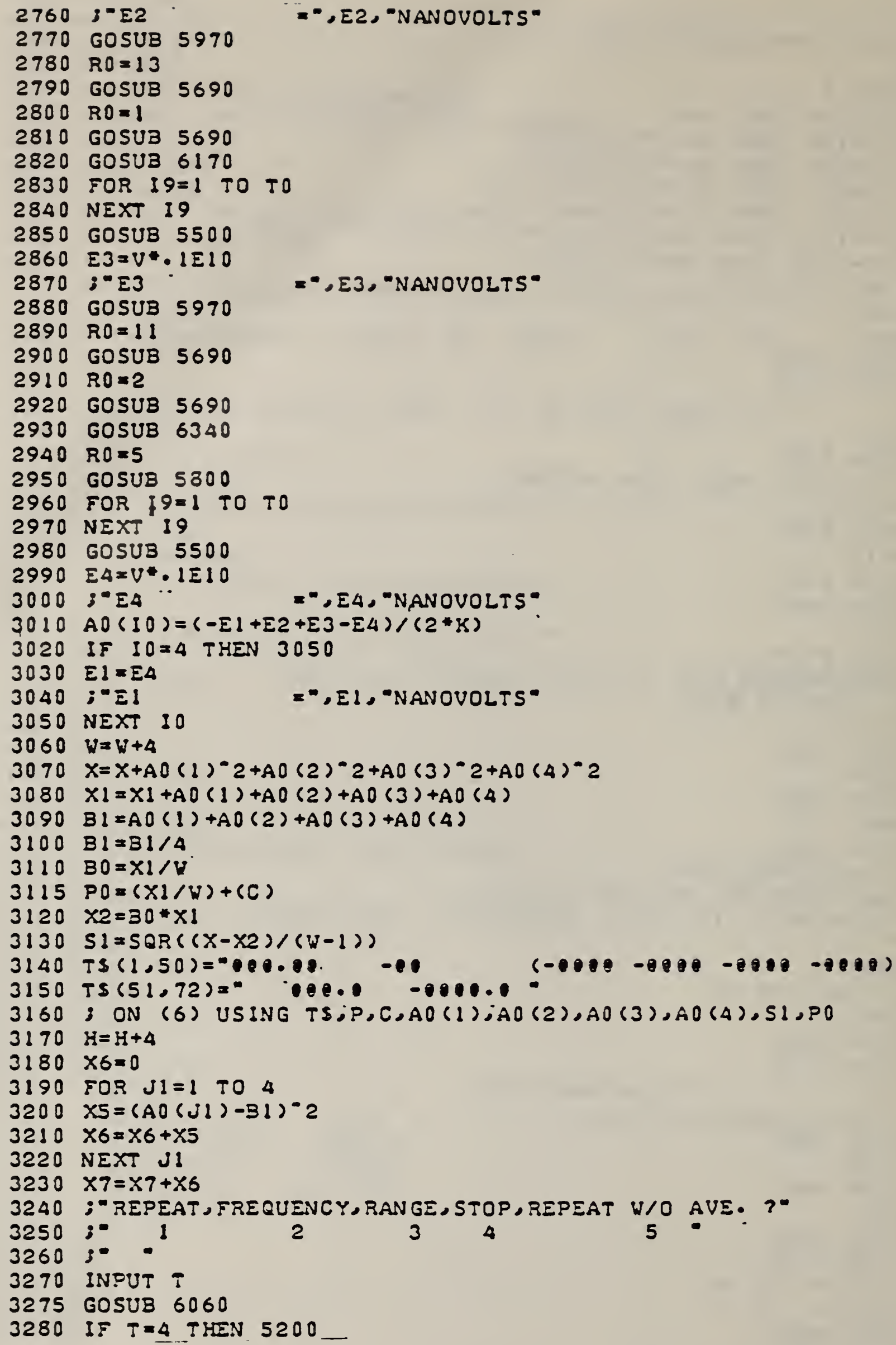


$3290 \quad M l=0$

3300 OS $=*<35>E 89: ;<=>$ \% $689: ;<=>$;

3310 CALL $1, M 0,05, U S, M 1, M 2$

3320 IF $T=1$ THEN 2330

3330 IF $T=2$ THEN 1510

3340 IF $T=3$ THEN 3360

3350 IF $T=5$ THEN 3380

$3360 \quad S=1$

3370 GOTO 1450

$3380 \times 7=\times 7-\times 6$

$3390 \mathrm{H}=\mathrm{H}-4$

3400 ; ON (6) "ABOVE DATA DELETED FROM TEST*

3410 GOTO 2160

3420 GOSUB 6060

$3430 ;$

3440

AC VOLTAGE SET

3450

3460

;******* IMPORTANT NOTE

;"WHEN SETTING AN AC VOLTAGE OF 1,10,0R 100 VOLTS, YOU MUSS"

3470

3480

3490

3500

3510

3520

3530

3540

3550

3560

3570

3580

3590

3600

$3610 \%$

$3620 \mathrm{D}=1$

3630 R0S $=" 6$ "

3640 GOSUB 6420

$3650 \mathrm{D}=0$

3660 :"TO SET VOLTAGE AND RANGE, FIRST INPUT THE CORRECT RANGE"

3670 ;"FOLLOWED BY THE 5-DIGIT VOLTAGE. A RANGE OF $0=1 \mathrm{MV}, 1=10 \mathrm{MV}, *$

$3680 ;-2=100 \mathrm{MV}, 3=1 \mathrm{~V}, 4=10 \mathrm{~V}, 5=100 \mathrm{~V}$, AND $6=1000 \mathrm{~V} 0^{\circ}$

3682 3" WHEN TEST LO \& HI AC MUST SET RANGE TO NEXT*

3684 ;- HIGHEST RANGE LIMIT FROM TEST VOLTAGE*

3686 ; (EX. 1 - TEST $\triangle Y$ AC SET RANGE AT $4=10 \mathrm{~V}$ OS"

3688 ; EX. 2 - TEST 100 V AC SET RANGE AT $6=1000$ )."

3690

3700

3710

3720

3730

3740

3750

3760

3770

3780

3790 OS $="\langle 35\rangle=\mathrm{FO}^{\circ}$ 
3800 CALL $1, M 0, O S, V S, M 1, M 2$

3810 GOTO 3880

3820 OS $={ }^{\circ}<35>C P^{*}+\operatorname{VOS}(1,5)+R O S+F O S+\cdots 20^{*}$

3830 ,

$3840 ;$ "CONNECT HIGH VOLTAGE AMP.,THEN RETURN"

3850 ;-

3860 INPUT G

3870 GOTO 3770

3880 "CHEC $K$ AC VOLTAGE AND FREQUENCY, IF CORRECT INPUT $1 \cdot, \cdot$

3890 -THEN RETURN: IF INCORRECT, INPUT '2 • OTHEN RETURN:"

3910 INPUT AS

3920 IF $A 5=1$ GOTO 3940

3930 GOTO 3420

$3940 ; “ I F$ FREQ. CHANGE INPUT 1 ', IF RANGE OR INITIAL RUN,RETURN* 3950

3960 INPUT A6

3970 IF AG=1 GOTO 2160

3980 IF ROS $={ }^{\circ} 6^{\circ}$ " GOTO 6060

3990 RETURN

$\triangle 000$ :-AC VOLTAGE CMECK"

$4010 \quad R 0=2$

4020 GOSUB 5690

4030 GOSUB 5400

4040 3V

$4050 \quad A 2=\bar{V}$

$4060 \quad A 2=A 2 * 1 E 9$

$\triangle 070 \mathrm{~V}=\mathrm{V}^{*}$. 1E9

4080 IF ABS $(A 2)<100$ THEN 4600

4090 IF US $(1,1)==^{-\infty}$ THEN 4350

4100 IF ROS $=0^{\circ} 4^{\circ}$ THEN 4140

4110 IF ROS ${ }^{\circ} 5^{\circ}$ THEN 4140

4120 IF ROS $=6^{\circ} 6^{\circ}$ THEN 4140 J

4130 GOTO 4150

4140 IF $\operatorname{VOS}(1,1)=-9^{-}$THEN 4170

$4150 \quad C 7=3$

4160 GOTO 4180

$4170 \quad C 7=40$

4180 A2 $=$ VAL (VOS)

$4190 \quad A 2=A 2-C 7$

4200 VOS $=$ STRS (A2)

$4210 \quad M 1=0$

4220 IF ROS=" 6" GOTO 4290

4230 OS $="<35>C P^{*}+\operatorname{VOS}(1,5)+R O S+F O S+\cdots 2^{*}$

4240 CALL $1, M 0,05, U S, M 1, M 2$

$4250 \mathrm{MI}=1$

4260 OS $=^{\circ}<35>70^{\circ}$

4270 CALL $1, M 0,05, V S, M 1, M 2$

4280 GOTO 4310

4290 OS $==^{-1}<35>C P^{*}+\operatorname{VOS}(1,5)+R O S+F O S+-20^{-}$

4300 GOTO 4270

4310 FOR $18=1$ TO 1500

4320 NEXT I8

4330 GOSUB 5400

4340 GOTO 4040 


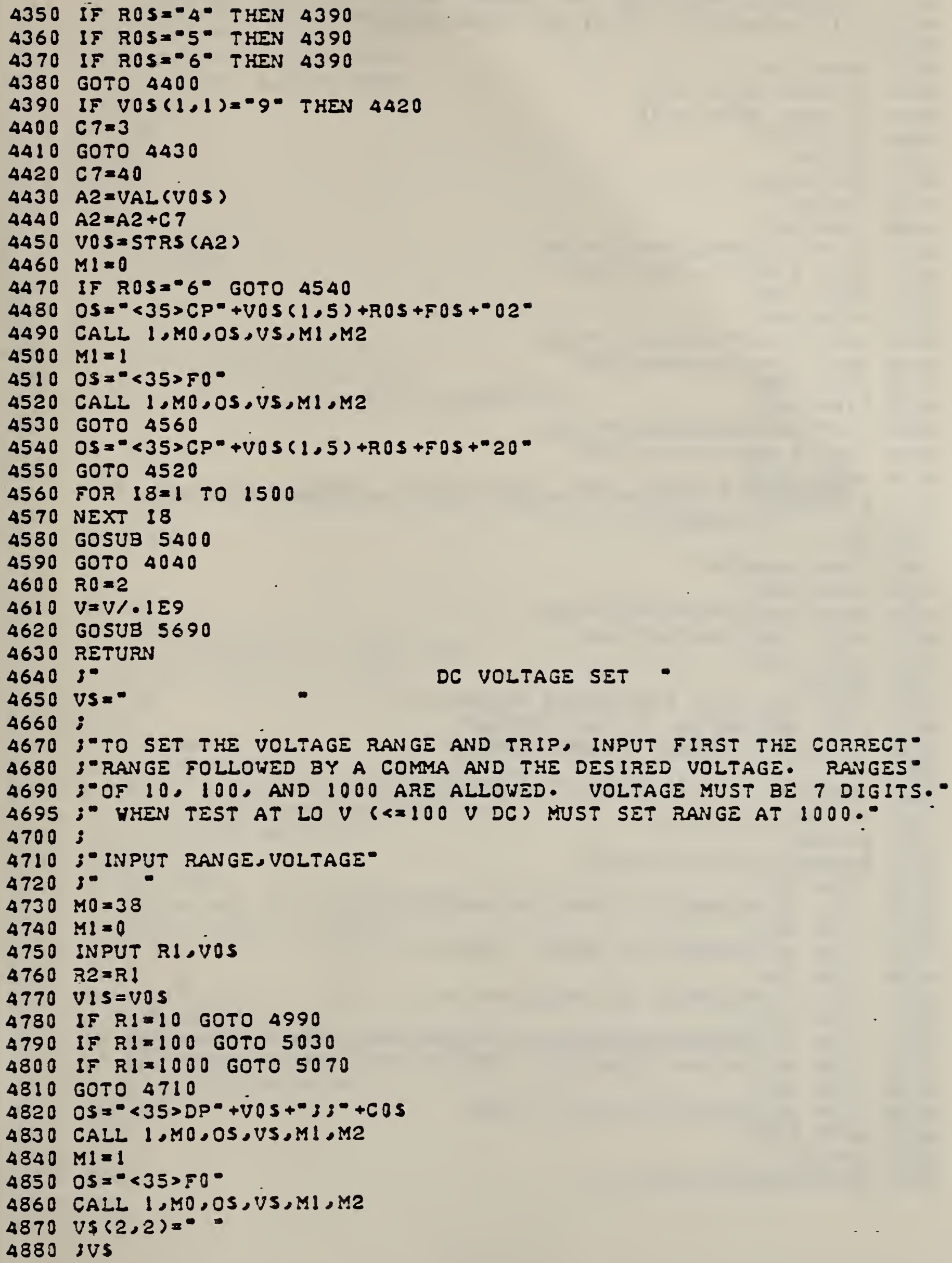




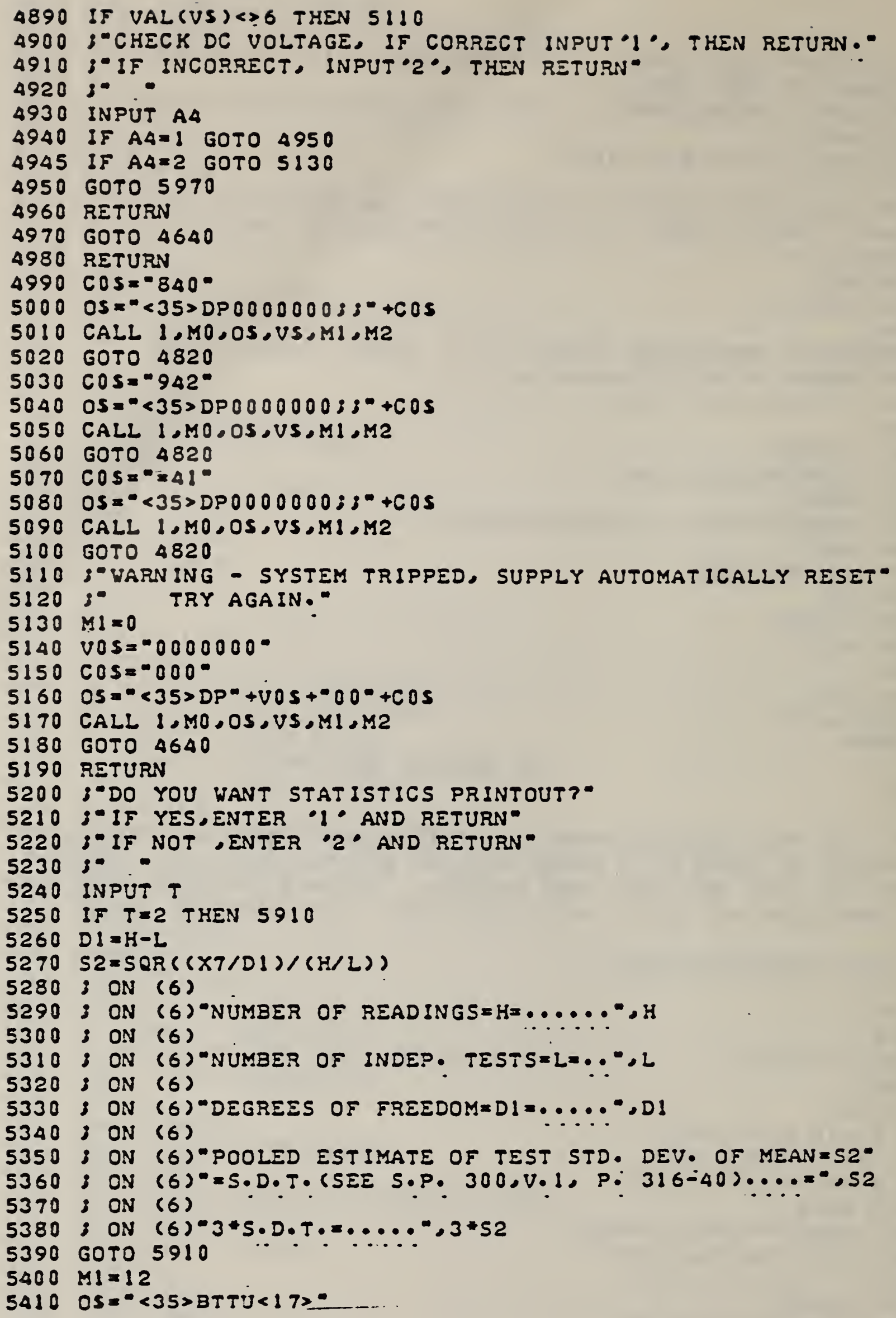




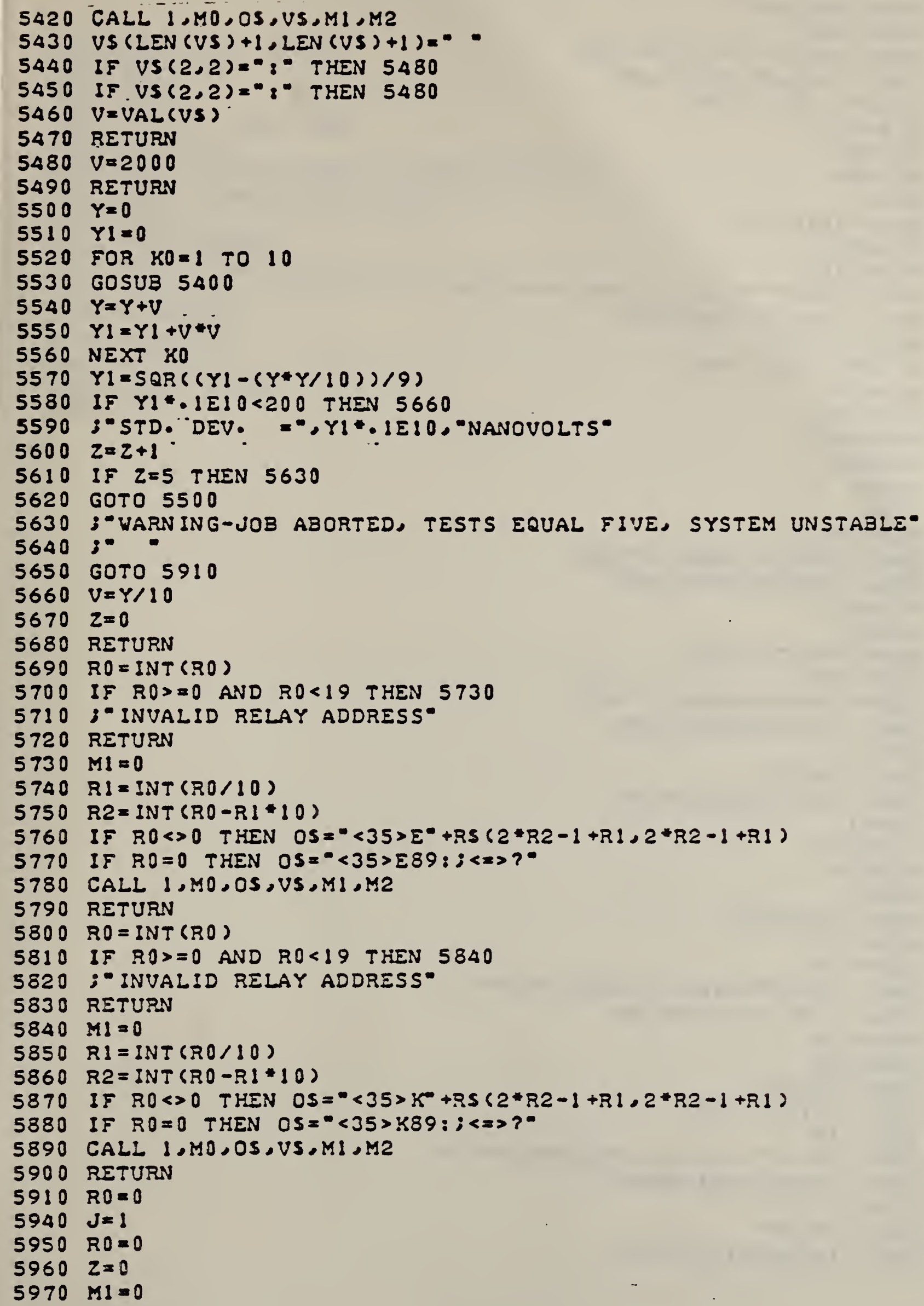




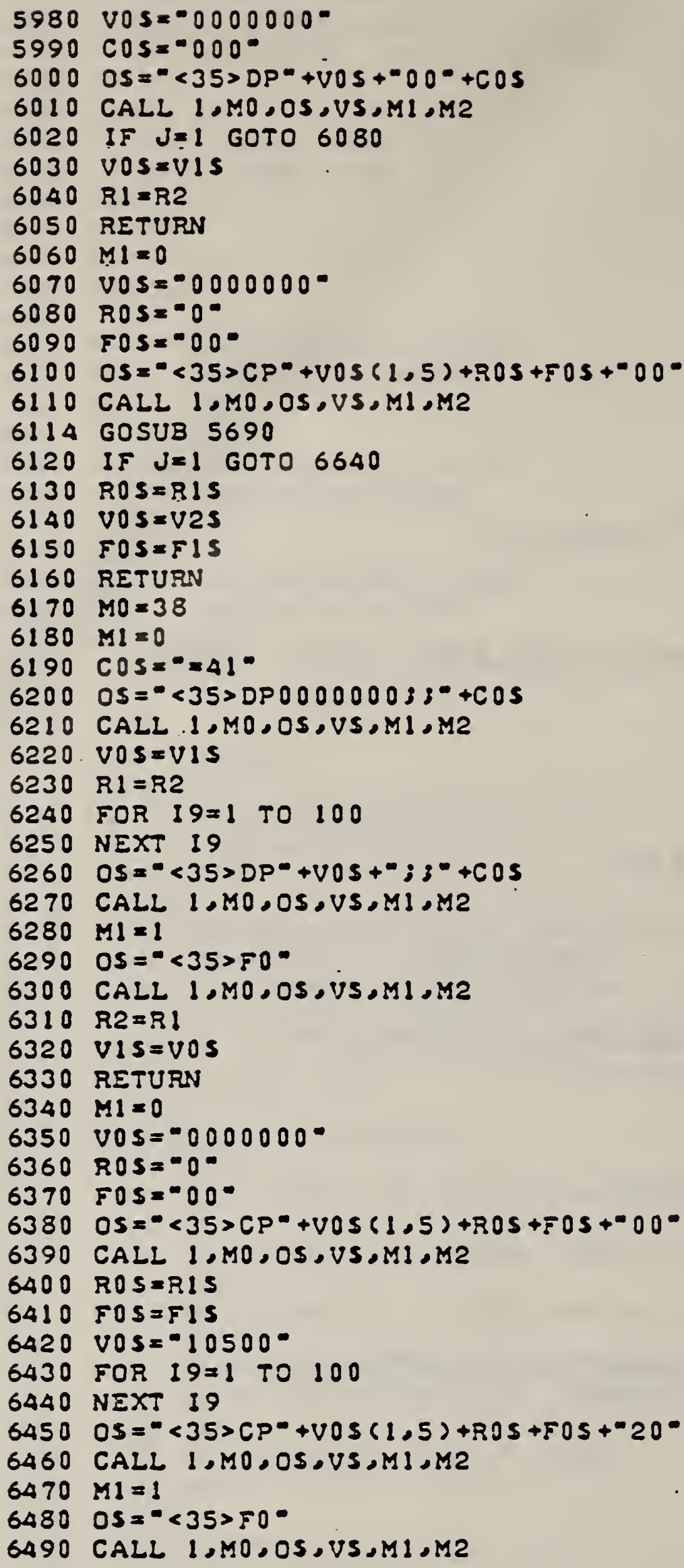




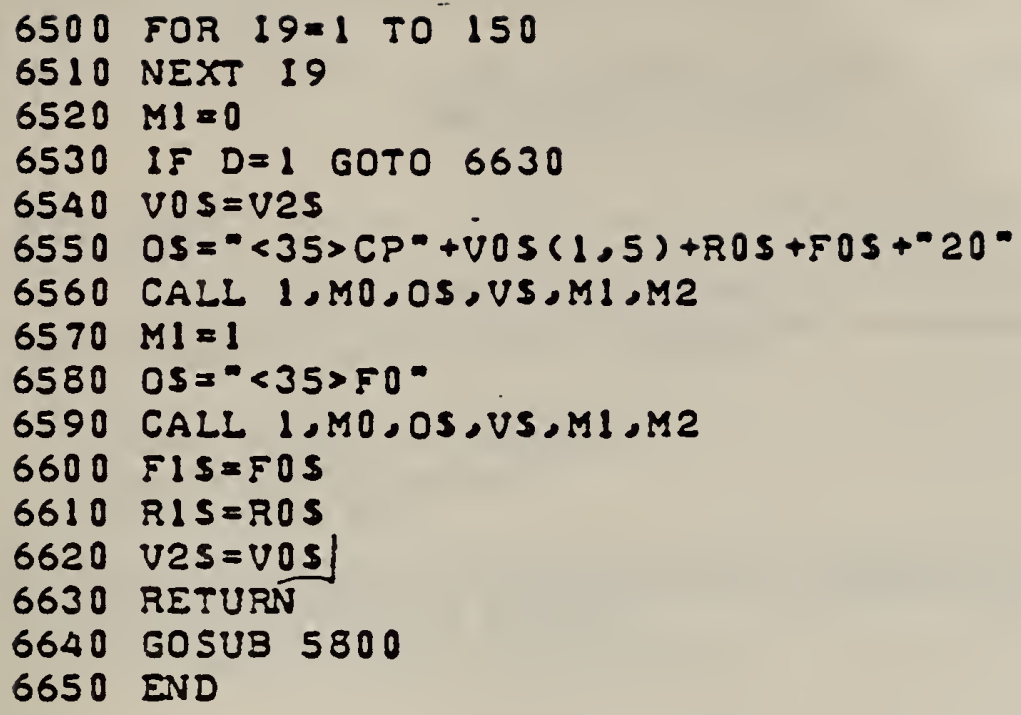


. 
NBS.114A (REV. 9-78)

\begin{tabular}{|c|c|c|c|}
\hline $\begin{array}{l}\text { U.S. OEPT. OF COMM. } \\
\text { BIBLIOGRAPHIC DATA } \\
\text { SHEET }\end{array}$ & $\begin{array}{l}\text { 1. PUBLICATION OR REPORT NO. } \\
\text { INBSIR } 82-2576\end{array}$ & 2.Gov't: Accession No. & 3. Reciptent's Accession No. \\
\hline \multirow{2}{*}{\multicolumn{3}{|c|}{$\begin{array}{l}\text { 4. TITLE AND SUBTITLE } \\
\text { A SEMIAUTOMATIC AC/DC THERMAL VOLTAGE CONVERTER } \\
\text { CALIBRATION SYSTEM }\end{array}$}} & $\begin{array}{l}\text { 5. Publication Date } \\
\text { September } 1982\end{array}$ \\
\hline & & & 6. Performing Organization Code \\
\hline \multicolumn{2}{|c|}{ K. J. Lentner and S. G. Trema ine } & & 8. Performing Organ. Report No. \\
\hline \multicolumn{3}{|c|}{ 9. PERFORMING ORGANIZATION NAME AND ADDRESS } & 10. Project/Task/Work Unit No. \\
\hline \multirow{2}{*}{\multicolumn{3}{|c|}{$\begin{array}{l}\text { 12. SPONSORING ORGANIZATION NAME AND COMPLETE ADDRESS (Street, City, State, zIP) } \\
\text { U.S. Department of Defense } \\
\text { Calibration Coordination Group }\end{array}$}} & $\begin{array}{l}\text { 13. Type of Report \& Period Covered } \\
\text { Final }\end{array}$ \\
\hline & & & 14. Sponsoring Agency Code \\
\hline
\end{tabular}

15. SUPPLEMENTARY NOTES

Document describes a computer program; SF-185, FIPS Software Summary, is attached.

16. ABSTRACT (A 200-word or less factual summary of most significant information. If document includes a significant bibliography or literature survoy, mention it here.)

A semiautomatic ac/dc difference calibration system is described. The system operates over a frequency range of $20 \mathrm{~Hz}$ to $100 \mathrm{kHz}$, covering the voltage range from $0.5 \mathrm{~V}$ to $1 \mathrm{kV}$. For all voltages at frequencies in the range from $20 \mathrm{~Hz}$ to $20 \mathrm{kHz}$, the total uncertainty is 50 parts per million (ppm), and $100 \mathrm{ppm}$ for voltages at frequencies between $20 \mathrm{kHz}$ and $100 \mathrm{kHz}$. In addition to ac/dc difference testing, the system can be readily adapted to calibrate precision ac digital voltmeters or ac calibrators. Results of extensive intercomparison testing of the new system against a manual test system are reported, using a multirange thermal transfer instrument as a transport standard. The results indicate that the ac/dc differences measured are well within the combined total uncertainty limits of the two systems.

17. KEY WORDS (six to tweive entries; alphabetical order; capitalize only the first letter of the first key iword unless a prope: name; separated by semicolons)

ac/dc difference; ac voltage measurement; automation; caitibration; metrology; thermal voltage converter.

18. AVAILABILITY

For Official Distribution. Do flot Release to NTIS

- Order From Sup. of Doc., U.S. Government Printing Office, Washington, DC 20402, SD Stock No. SNOO3-003-

X Order From National Technical Information Service (NTIS), Springfield, VA. 22161

\begin{tabular}{|l|c|}
\hline $\begin{array}{l}\text { 19. SECURITY CLASS } \\
\text { (THIS REPORT) } \\
\text { UNCLASSIFIED }\end{array}$ & $\begin{array}{c}\text { 21. ND. OF } \\
\text { PRINTED PAGES }\end{array}$ \\
\hline $\begin{array}{l}\text { 20. SECURITY CLASS } \\
\text { (THIS PAGE) }\end{array}$ & $\begin{array}{l}22 . \text { Price } \\
\text { UNCLASSIFIED }\end{array}$ \\
\hline
\end{tabular}


